\title{
Investigation of Spatial Risk Factors for RVF Disease Occurrence Using Remote Sensing \& GIS-A Case Study: Sinnar State, Sudan
}

\author{
Kowther Mohamed Saeed Ahmed', Amna Ahmed Hamid' ${ }^{2}$, Abbas Doka ${ }^{3}$ \\ ${ }^{1}$ Remote Sensing \& Geographical Information System Master Program, Sudan Academic of Sciences (SAS), \\ Khartoum, Sudan \\ ${ }^{2}$ Remote Sensing \& Geographical Information System Program, Remote Sensing Authority-National Center for \\ Research, Khartoum, Sudan \\ ${ }^{3}$ College of Agricultural Studies, Sudan University of Science \& Technology, Khartoum, Sudan \\ Email: kowthersaeed@yahoo.com, amnaah71@gmail.com, adoka21@gmail.com
}

Received 4 February 2015; accepted 18 April 2015; published 22 April 2015

Copyright (C) 2015 by authors and Scientific Research Publishing Inc.

This work is licensed under the Creative Commons Attribution International License (CC BY).

http://creativecommons.org/licenses/by/4.0/

(c) (†) Open Access

\section{Abstract}

Rift Valley Fever (RVF) is an emerging, mosquito-borne disease with serious economical and negative implications on human and animal health. This study was conducted to verify the factors which influenced the spatial pattern of Rift Valley Fever occurrence and identified the high risk areas for the occurrence of the disease at Sinner State, Sudan. The normalized difference vegetation index (NDVI) derived from Moderate Resolution Imaging Spectroradiometer (MODIS) satellite and rainfall data in addition to the point data of RVF clinical cases in humans were used in this study. In order to identify the RVF high risk areas, remote sensing data and rainfall data were integrated in a GIS with other information including, soil type, water body, DEM (Digital Elevation Model), and animal routes and analyzed using Spatial Analysis tools. The information on clinical cases was used for verification. The Normalized Difference Vegetation Index (NDVI) was used to describe vegetation patterns of the study area by calculating the mean NDVI. The results of the study showed that, RVF risk increased with the increase in vegetation cover (high NDVI values), and increase in rainfall, which both provided suitable conditions for disease vectors breeding and a good indicator for RVF epizootics. The study concluded that, identification of high risk area for RVF disease improved the understanding of the spatial distribution of the disease and helped in locating the areas where disease was likely to be endemic and therefore preparedness measures should be taken. The identification represents the first step of prospective predictions of RVF outbreaks and provides a baseline for improved early warning, control, response planning, and mitigation. Further detailed studies are recommended in this domain. 


\section{Keywords}

\section{Rift Valley Fever, Vector-Borne Diseases, Spatial Risk Factors, Normalized Difference Vegetation Index (NDVI)}

\section{Introduction}

Rift Valley Fever (RVF) is an acute and febrile viral Zoonotic disease caused by a virus, which belongs to the family Bunyaviridae and the genus Phlebovirus [1]. RVF is a serious disease with serious financial, economic, social and public health implications. In this regard, RVF affects the livestock trade according to the international list of the Office of Epidemiology. The virus is primarily a vector-borne zoonotic pathogen. Humans acquire RVF through bites by infective mosquitoes or, more frequently, through exposure to virus contaminated blood, body fluids, or tissues of animals that have been bitten by infected mosquitoes. Direct infection of animals can occur during exposure of slaughter live or through veterinary and obstetric procedures. Outbreaks in Livestock can occur following heavy rainfall and flood that result in hatching of Aedes (Stegomyia) mosquitoes eggs which are usually existing in the cracks and holes in the ground (thought to be the initial vector and inter-epizootic reservoir of RVF). Adult mosquitoes which happen to be infected then feed any nearby mammals. First outbreak RVF disease was reported in Sudan during June to December 1973: extensive epizootic involving sheep, goats and cattle in Kosti (White Nile), Eldueim and Sinner and as well informal reports of human cases.

Epidemiologists, public health professionals, medical geographers have traditionally used maps when analyzing associations between location, environment, and disease [2]. Remote sensing data coupled with Geographic Information System (GIS) are well suited for studying these associations because of their capabilities for locating, analyzing and display of spatial information.

- The study was carried out in Sinner State-Sudan which was affected by RVF disease outbreak in year 2007. The aim of the study was to identify the environmental risk factors associated with RVF disease, to investigate factors that influenced the spatial pattern of RVF during year 2007 outbreak, and to produce RVF disease risk map (high risk area). Rift Valley Fever occurrence is mainly based on the hypothesis that heavy rainfall is in low laying areas with dense vegetation. Such an environmental condition is likely to increase the occurrence RVF disease. Climate change in Sudan and neighboring countries provides a good environment for this kind of epidemics vectors-borne disease.

- Remote sensing data, climatic data, environmental data, and field observation points that represent the clinical signs in human outbreak of RVF disease in Sinner 2007 were integrated in a GIS and analyzed to assess RVF Risk in Sinner state and to produce RVF disease risk map. A risk factor is something likely to increase the chances that a particular event will occur. Risk maps show the spatial distribution of disease risk, i.e. how probabilities of outbreak vary over a given area, based on the location of risk factors as well as their relative importance. Data-driven risk maps show absolute risk estimates whereas knowledge-driven risk maps show relative risk scores (they identify areas at higher or lower risk of disease occurrence). This approach needs to be based on available evidence [3]. The study was conducted to achieve the following objectives:

To identify the environmental risk factors associated with RVF disease.

To investigate factors that influenced the spatial pattern of RVF during year 2007 outbreak.

To map RVF disease distribution in Sinnar (outbreak, 2007).

To produce RVF disease risk map (high risk area).

\section{Material and Methods}

\subsection{Study Area}

This study was carried in Sinner State, which is located in the south-eastern part of the country between the latitudes $12^{\circ} 5^{\prime}$ and $14^{\circ} 7^{\prime}$ and longitudes $32^{\circ} 58^{\prime} \mathrm{N}$ and $35^{\circ} 42^{\prime} \mathrm{E}$. The capital of the state is Singa, which lies 360 kilometers southeast of Khartoum State. The area of the State is approximately 40,680 square kilometers The State was composed of seven localities. Figure 1 is the location map of the study area. 


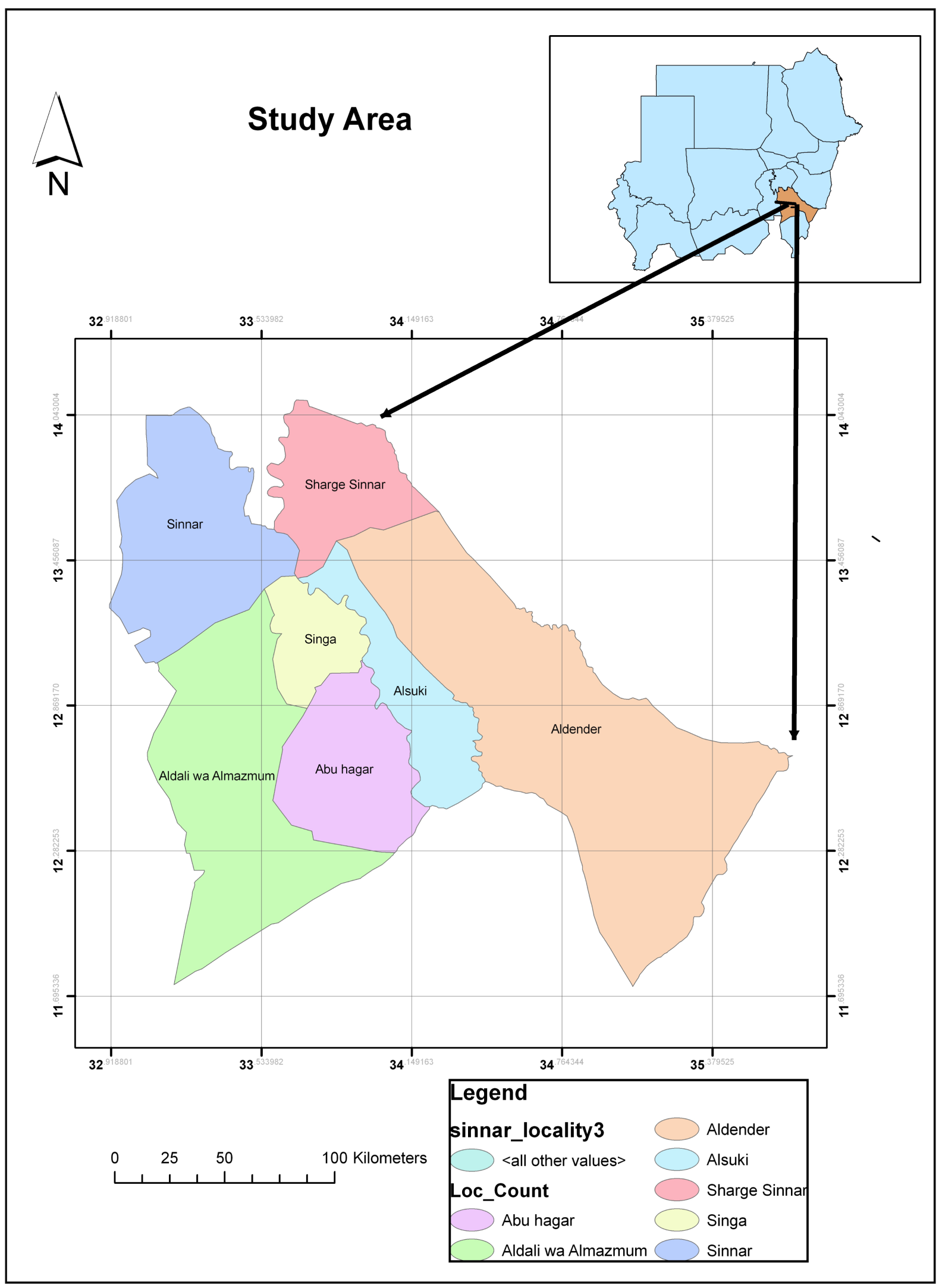

Figure 1. The location map of the study area. 
It is characterized by continental climate and it is located in the savanna belt with rainfall ranges from 300 $\mathrm{mm}$ in the north to $800 \mathrm{~mm}$ in the south. The study area is rich in surface water and groundwater. The main source is the Blue Nile and temporary water bodies which increase with rainfall during the rainy season, these temporary water bodies are favorable breeding and resting sites for Aedes and mosquitoes, and are also the main water sources for pastoral populations and their herds. The human population varies according to the different locality as shown by Figure 2 human animal population, settlements and hospitals.

\subsection{Material and Methods}

The materials used in this study include human cases of RVF data collected from the site of infection by weekly reports; reporting human clinical cases depending on the description of case definition of RVF case (which is characterized by fever satisfactory severe (more than $37.5^{\circ} \mathrm{C}$ in mouth more than $38^{\circ} \mathrm{C}$ ) for a period of more than 48 hours and vomiting or diarrhea without response to antibiotics and treatments of malaria and be accompanied by manifestations of bleeding under the skin of wounds and mucous membrane of nose, gastrointestinal tract, or of the vagina with a possibility of abortion. In addition to: Dealing directly with infected pets (or dead) or with secretions or products and Travel during the previous week to an area where there is an epidemic of Rift Valley fever [4] NDVI images extracted from MODIS $250 \mathrm{~m}$ resolution in year 2007 to 2012 [5], different thematic maps; natural resources data including landform and meteorological data [6] and statistical data composed of clinical cases of RVF, human and animal populations. As well, GIS Software Arc GIS9.3 and ENVI 4.5 remote sensing software were also used. RVF risk map was produced through different steps and analysis procedures that relate the risk factors with the disease and to each other using Arc GIS and ENVI software analysis, Function.

MODIS images were used to extract NDVI in the study area using Raster Calculation Function in ENVI 4.5 software. The function, operation in ENVI was applied to produce an average NDVI image of the study area in 2007 at the time when the disease occurred and compared with years from 2008 to 2012. A Number of Environmental factors that are considered to be associated with RVF disease risk were identified and prepared as GIS layers that are ready to be used for the analysis.

The different data layers including buffer zones, animal routes, soils units, DEM [7] reclassify and clinical points were geo-referenced and converted to raster overlay the animal route and percentage clinical cases compared by locality in Sinnar State shown by (Figure 3). Two fields was added to the attribute table of clinical cases (Shape file) which identify the NDVI, Rainfall Values that are correspond to the human disease clinical case Points, Shown by (Figure 4, Figure 5), (Figure 6) represent topographic position (DEM) corresponding to human cases and DEM conducted terrain processing using Arc hydro extension Shown by (Figure 7).

All the remote sensing layers rainfall (Figure 8), NDVI (Figure 9), water body (Figure 10), soil type (Figure 11), DEM (Figure 12), animal routes (Figure 13) were made spatially ready and integrated in GIS together with clinical information. Different functionalities of GIS were used to analyze the data to create one layer meeting all criteria which classified to (very low, low, medium and very high).

\section{Results and Discussion}

This study investigated and identified the environmental factors that influence the spatial pattern of RVF Risk (Outbreak 2007) and located high risk areas of RVF, shown in Figures 14-16 and Figure 17. The correlation between RVF disease and the environmental factors according to research finding are as follow:

\subsection{Heavy Rainfall and Water Bodies}

An epizootic of RVF is generally observed during years in which unusually heavy rainfall and localized flooding occur. The excessive rainfall allows mosquito eggs, usually of the genus Aedes, to hatch. The mosquito eggs are naturally infected with the RVF virus. Average rainfall data (2007) range between (300 - $800 \mathrm{~mm}$ ) and were classified into 5 categories, very high, high, medium, low and very low. Figure 3 shows Rainfall 2007 classes associated with clinical cases. RVF Risk areas are associated with rainfall equal and greater than $500 \mathrm{~mm}$, which confirms that about $85 \%$ of RVF cases occur within this range. Water bodies and the surrounding flooded territory associated with alluvial riverine floodplains represent risk areas because they are associated with source of mosquitoes Aedes eggs as shown by Figure 10. Epizootics and epidemics are associated with periods of heavy 


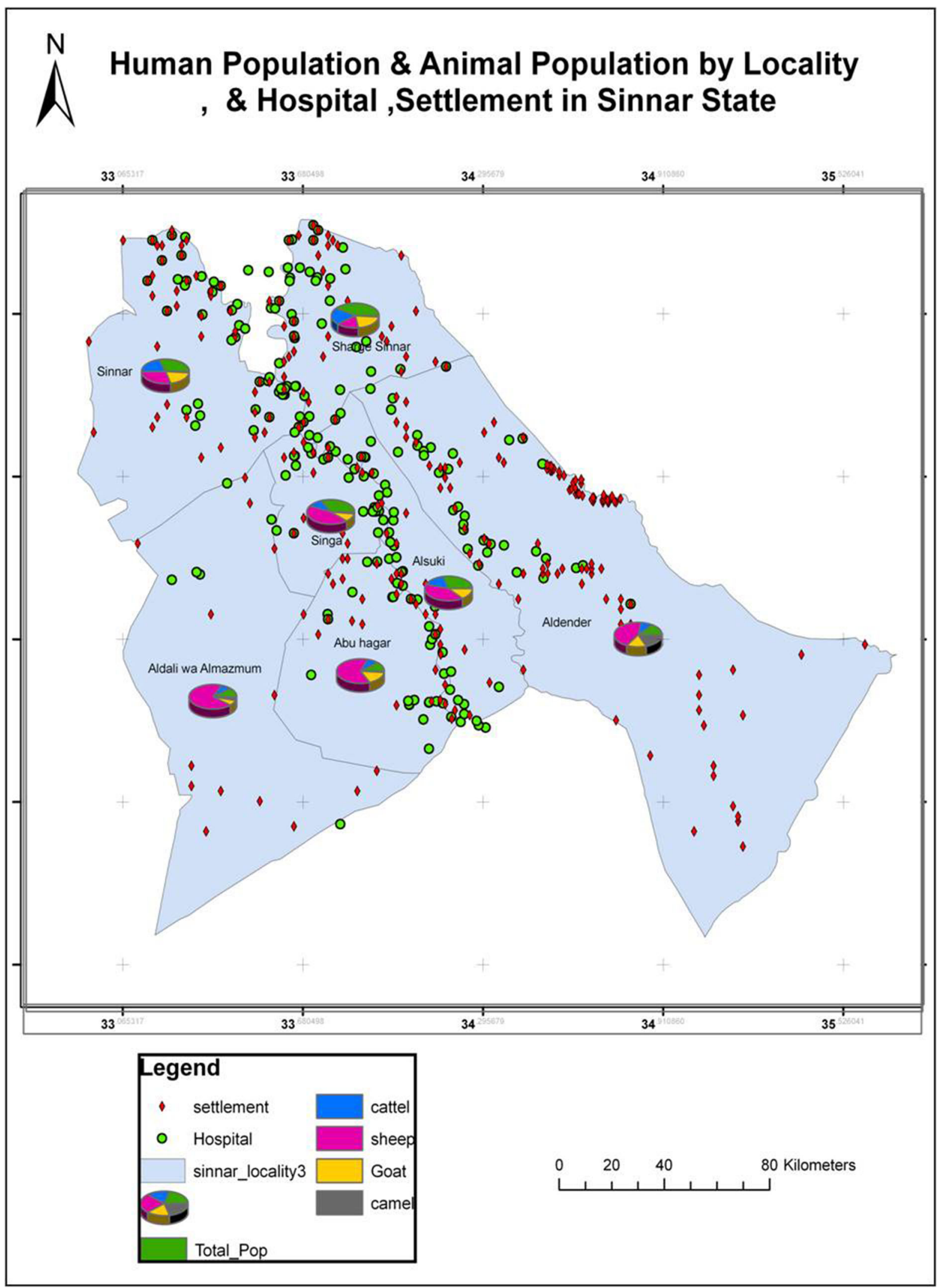

Figure 2. Human animal population, settlements and hospitals. 


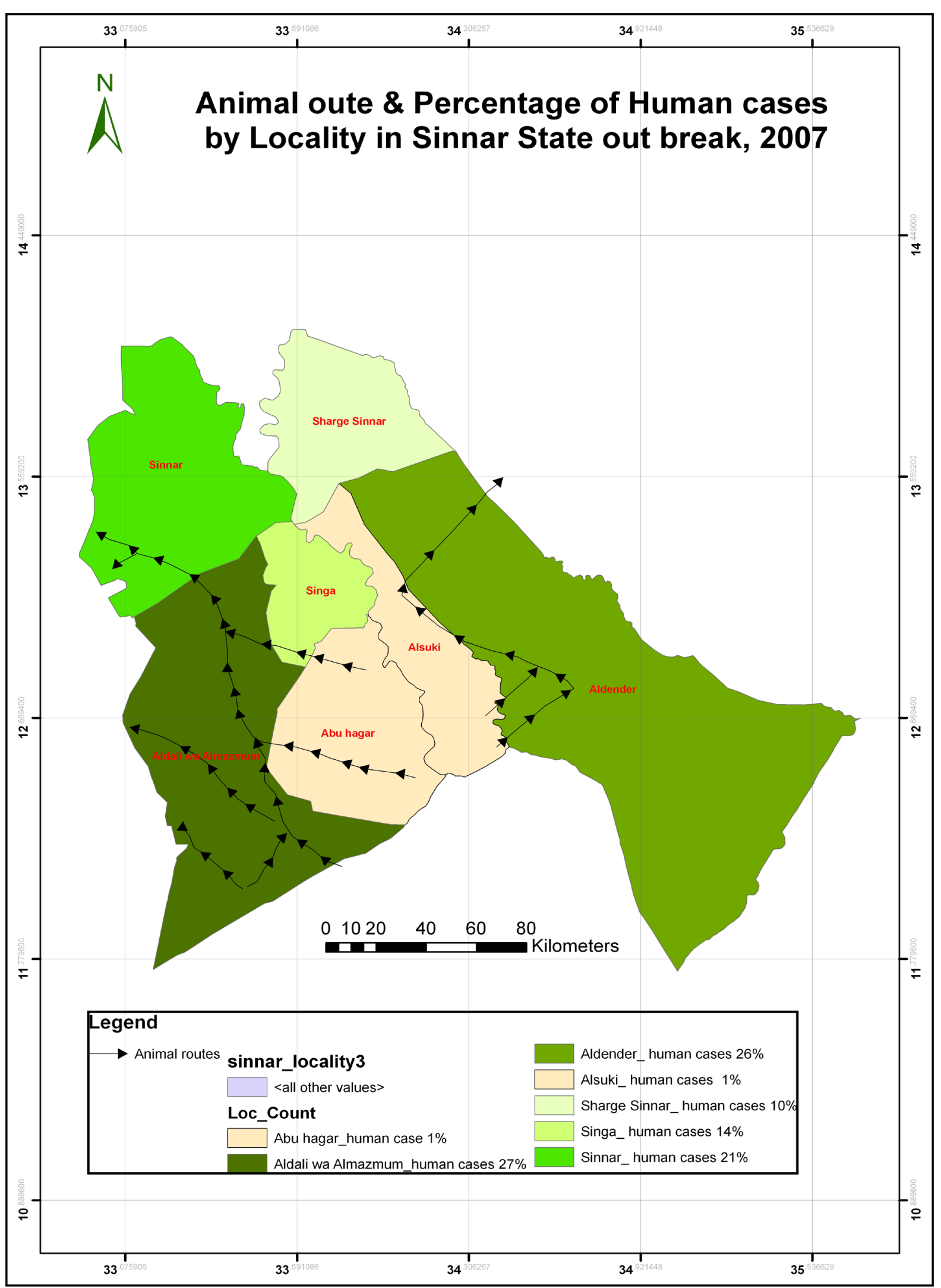

Figure 3. Market points, Animal route, and clinical cases by locality in Sinnar. 


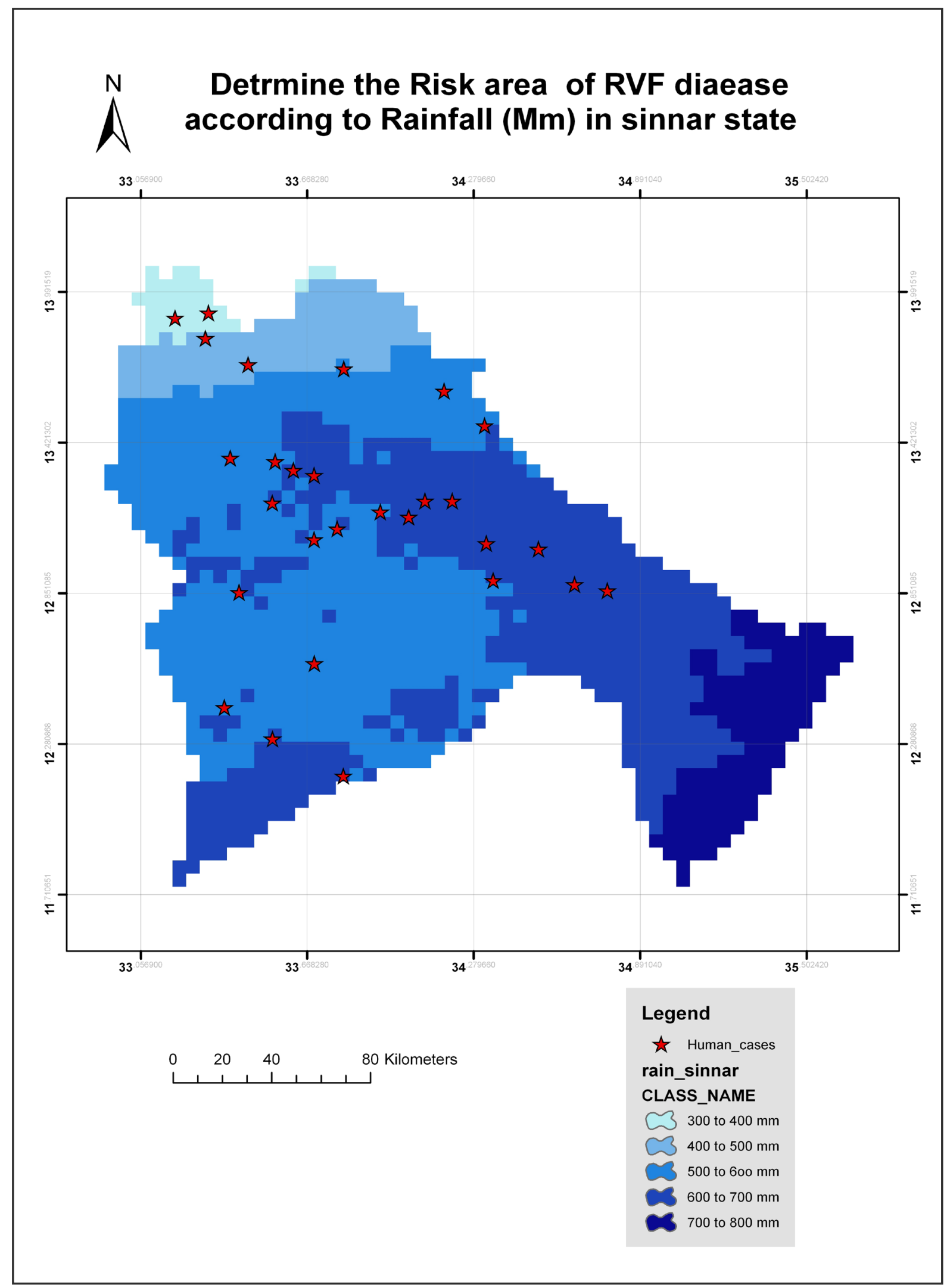

Figure 4. Rainfall 2007 associate with clinical cases. 


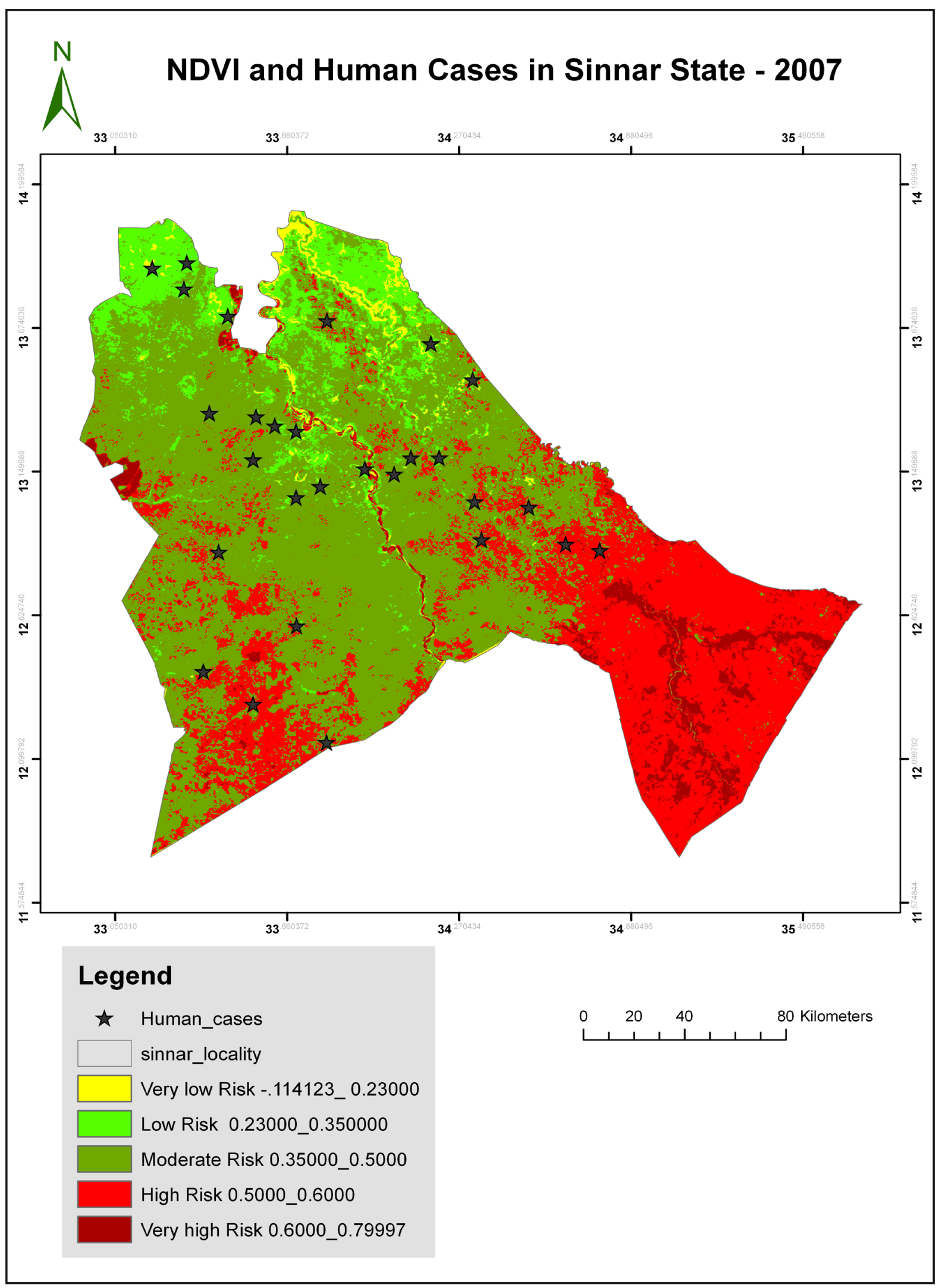

Figure 5. NDVI average 2007 associate with clinical cases. 


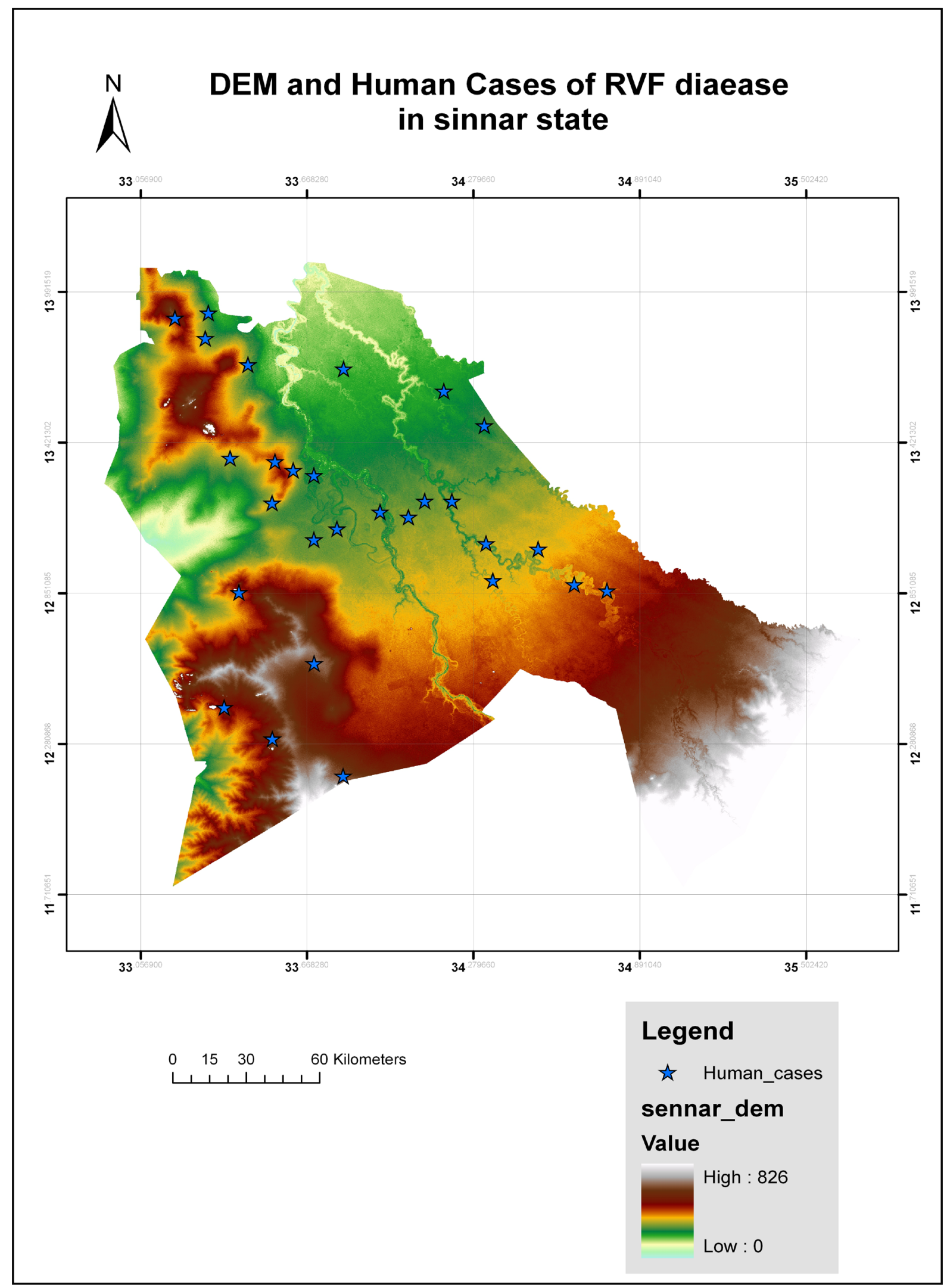

Figure 6. DEM associate with clinical cases. 


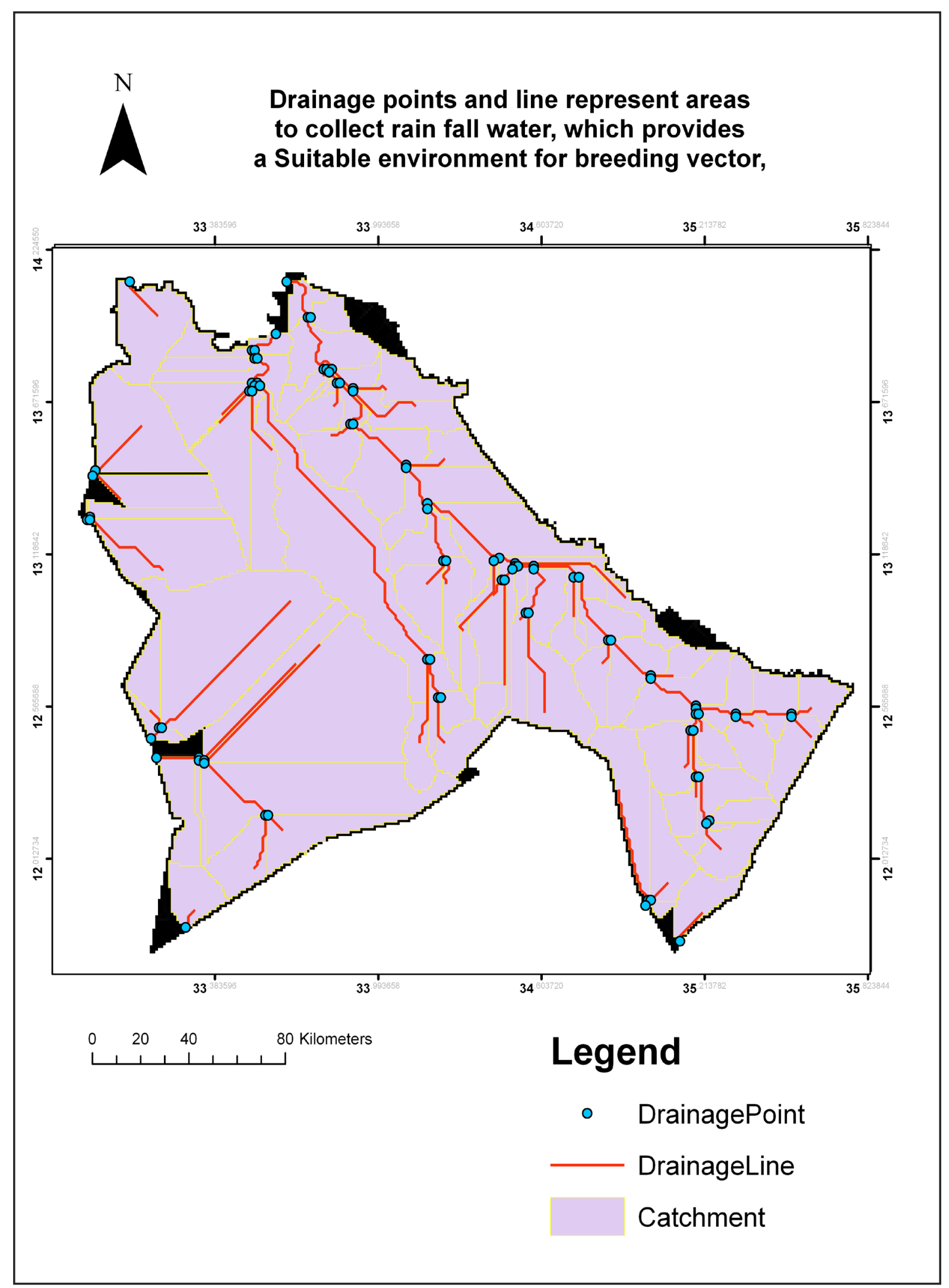

Figure 7. Terrain processing, hydrology of Sinnar State. 


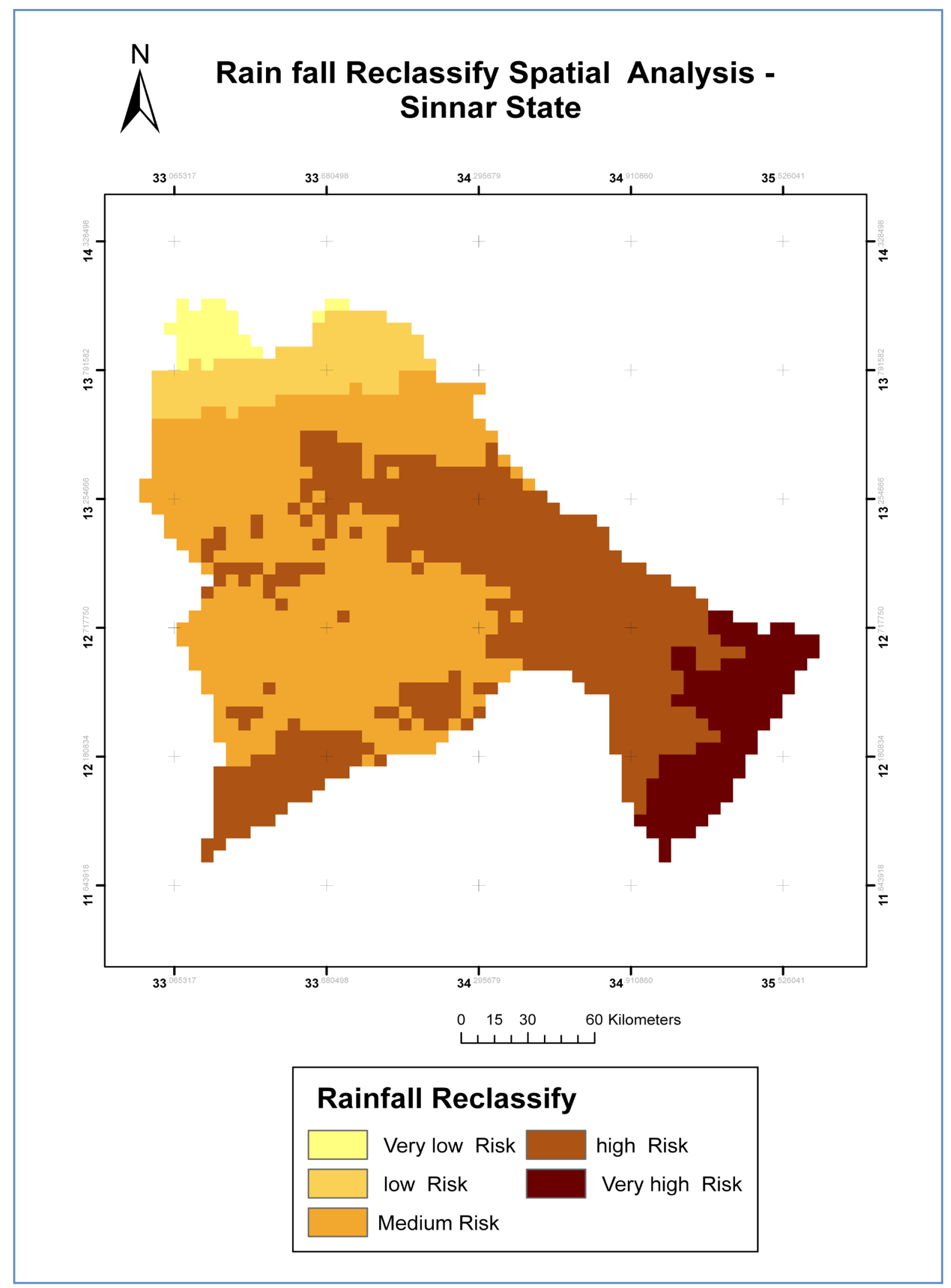

Figure 8. Reclassify rainfall raster layer 2007. 


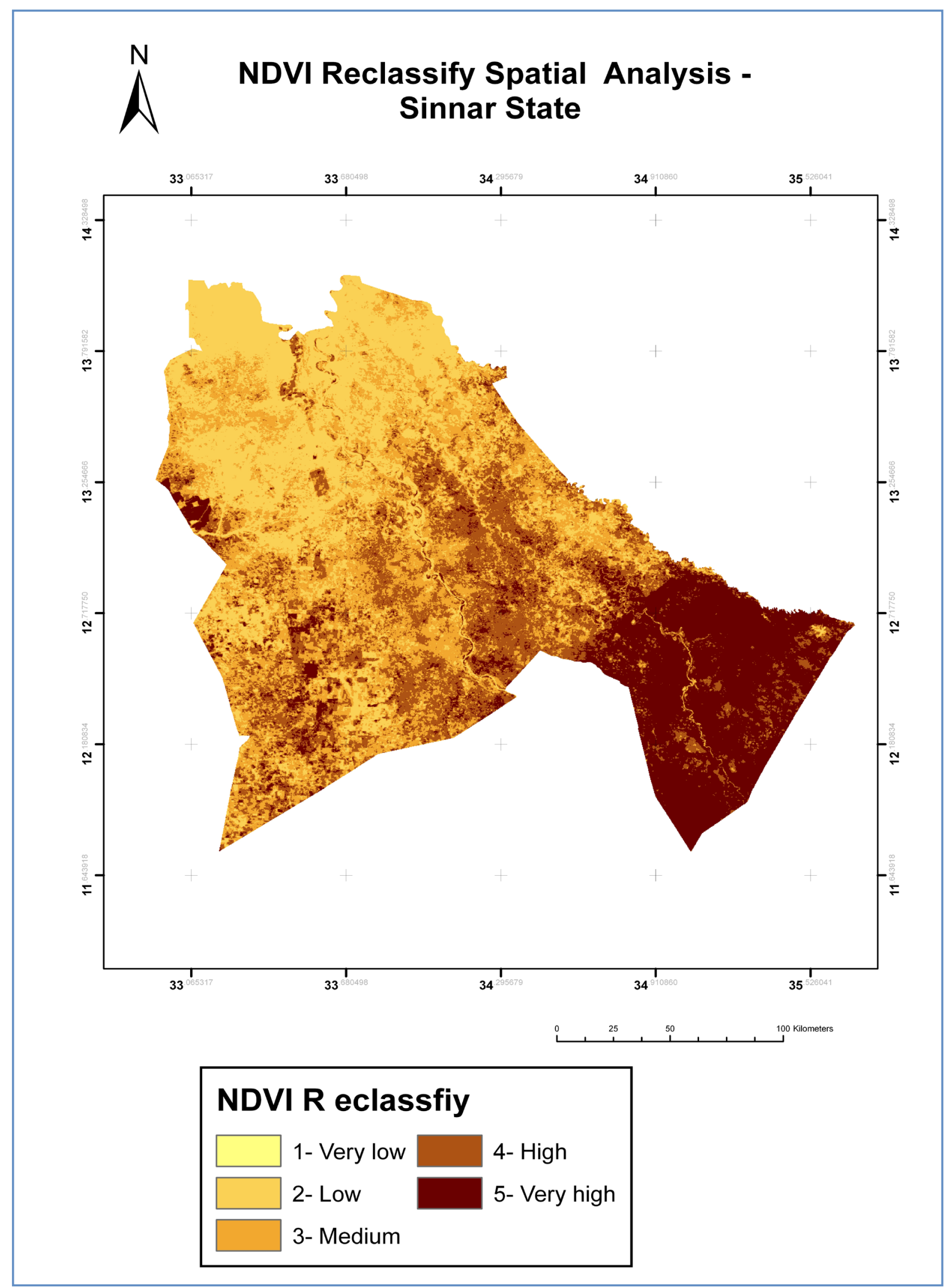

Figure 9. Reclassify NDVI raster layer 2007. 


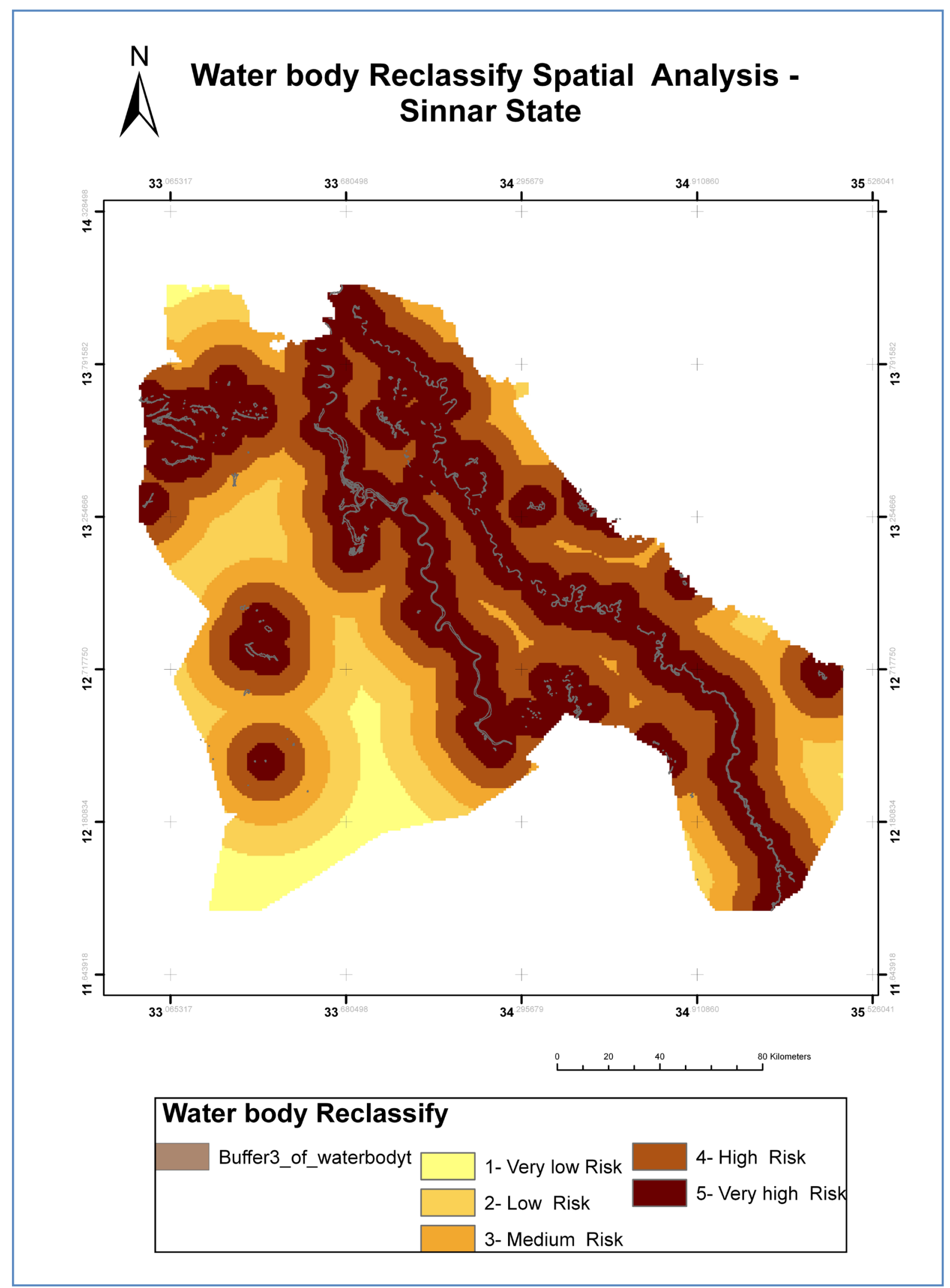

Figure 10. Reclassify water body distance raster layer. 


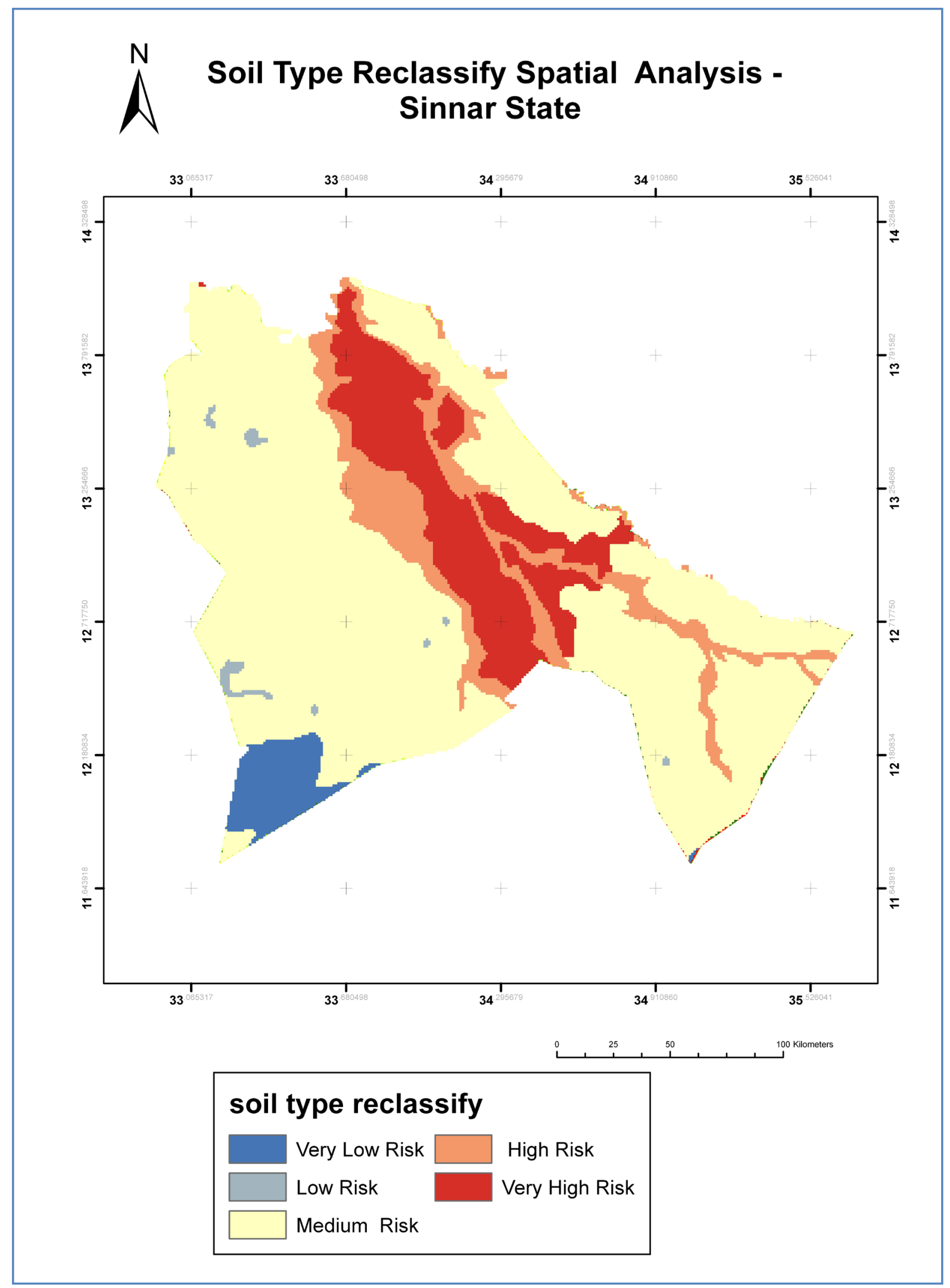

Figure 11. Reclassify soil type raster layers. 


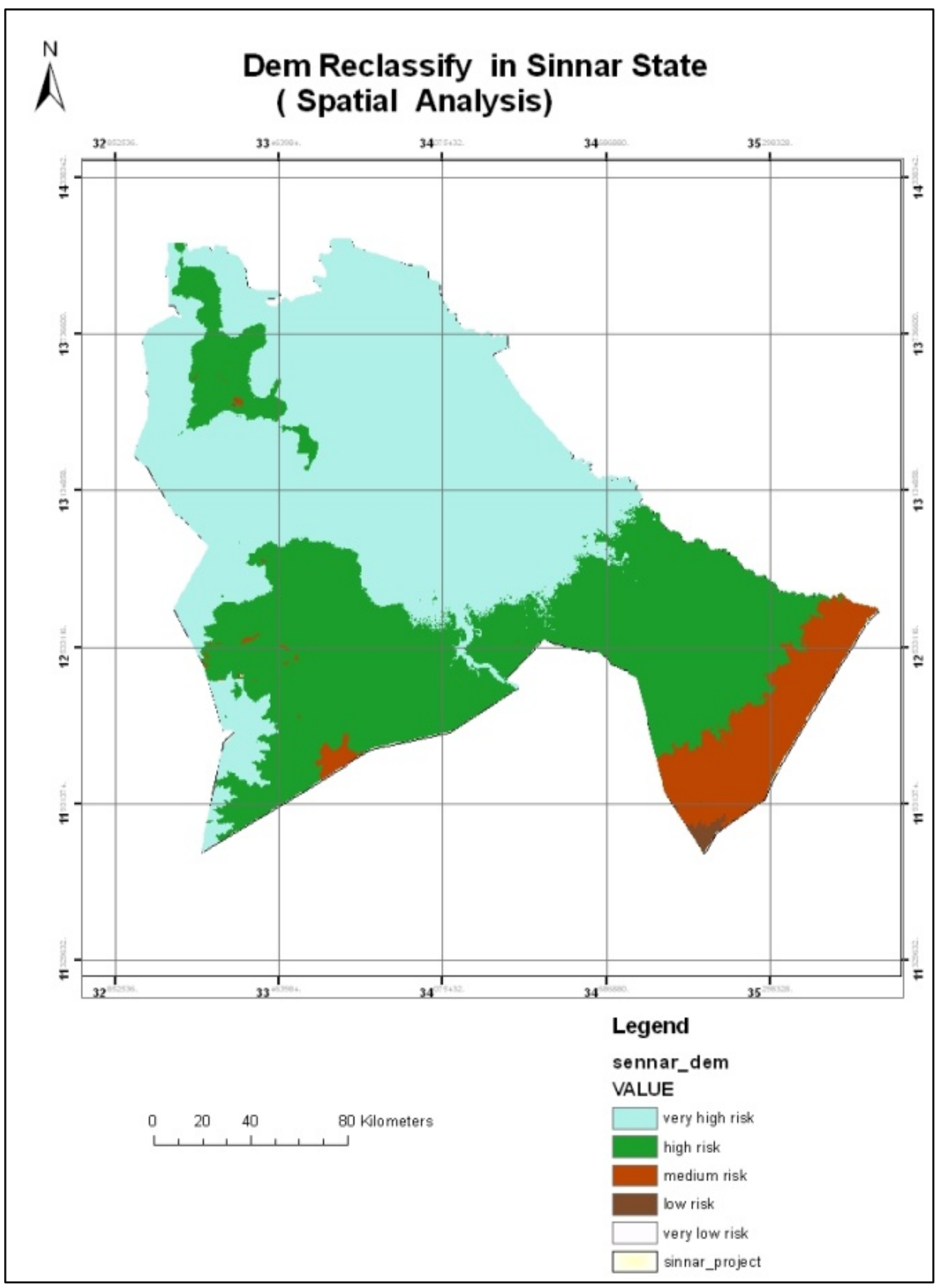

Figure 12. Reclassify DEM raster layers. 


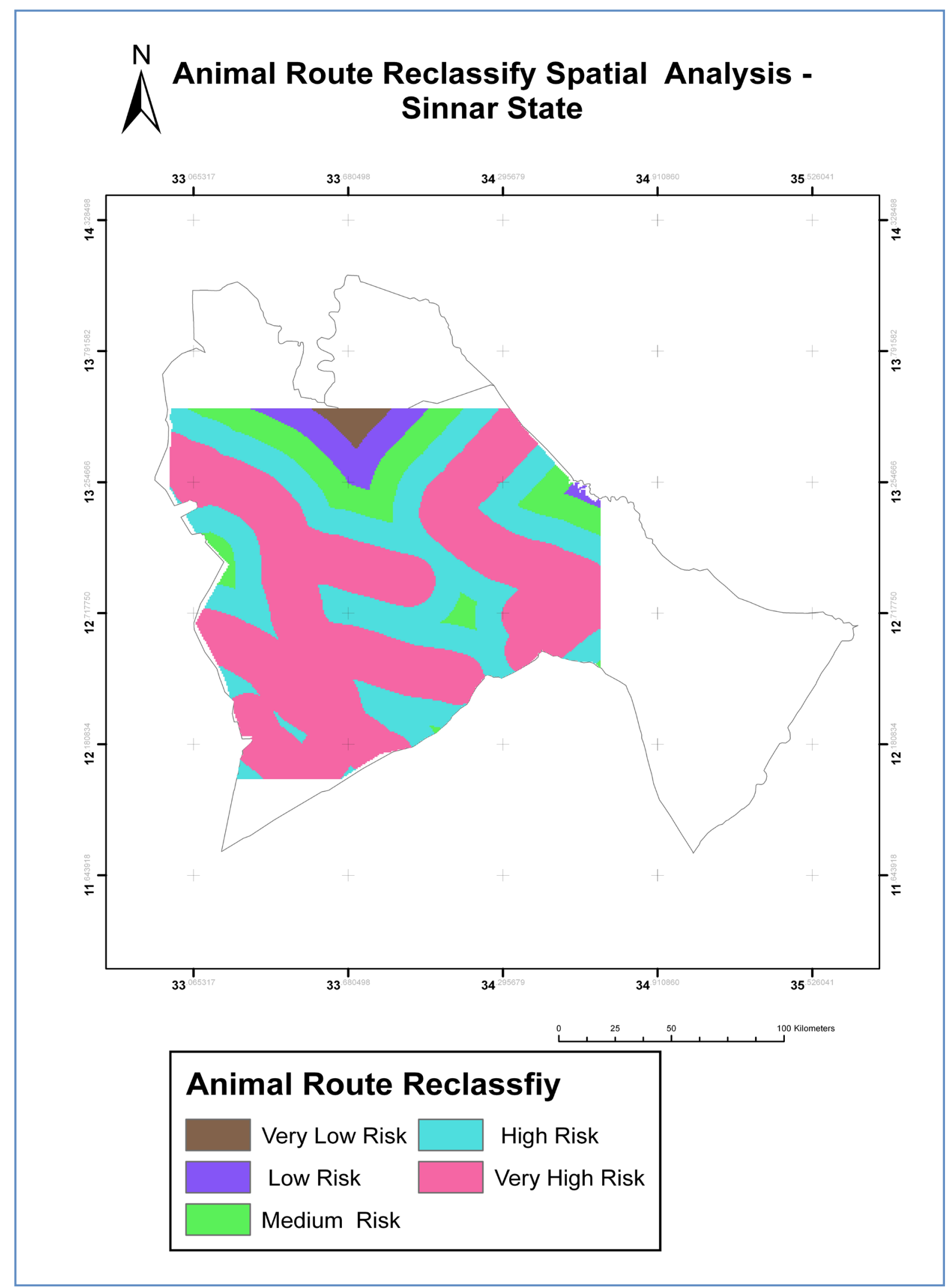

Figure 13. Reclassify animal route raster layers. 


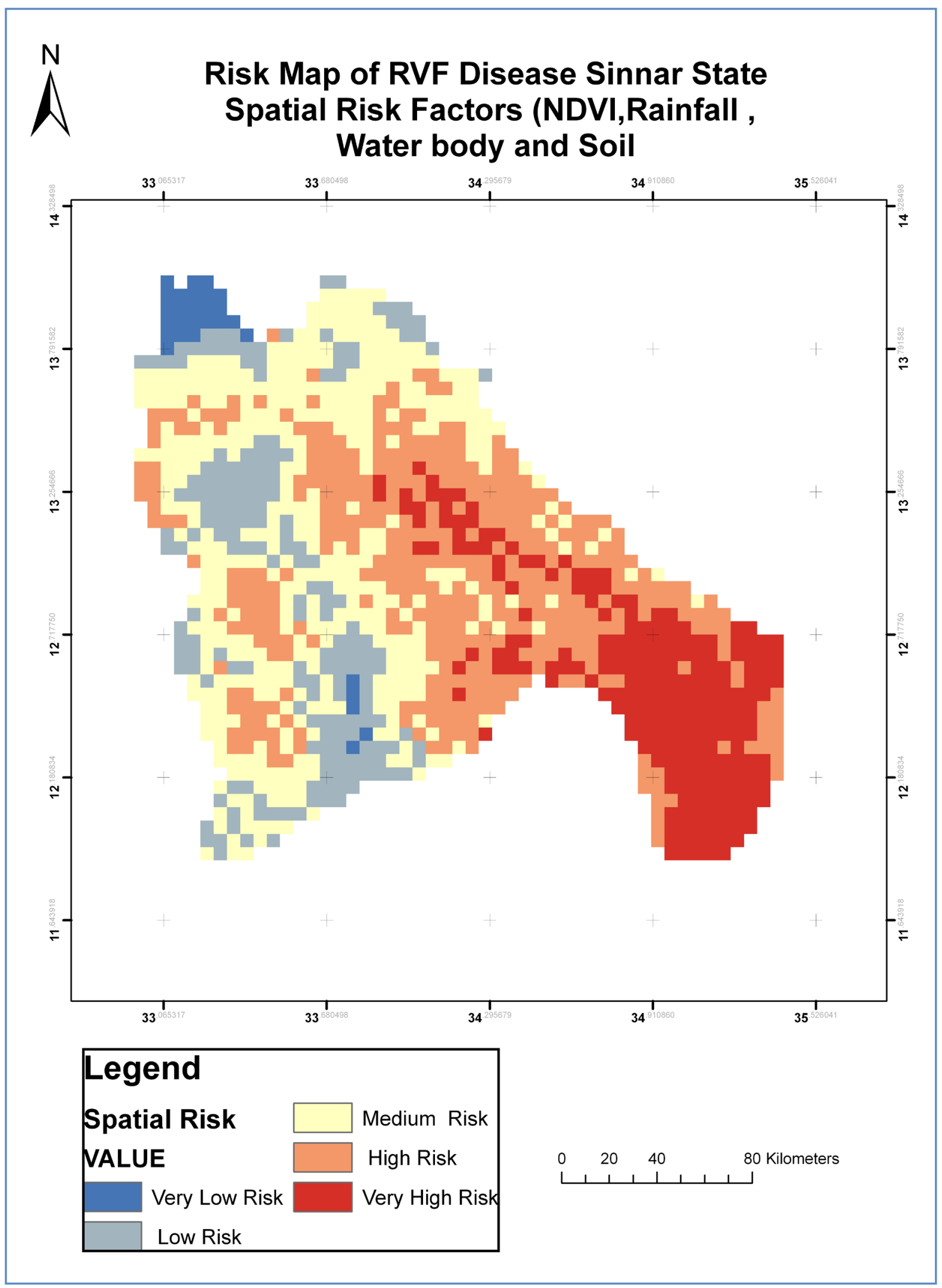

Figure 14. Risk map of RVF disease 2007 by Raster calculation combine environmental risk factors. 


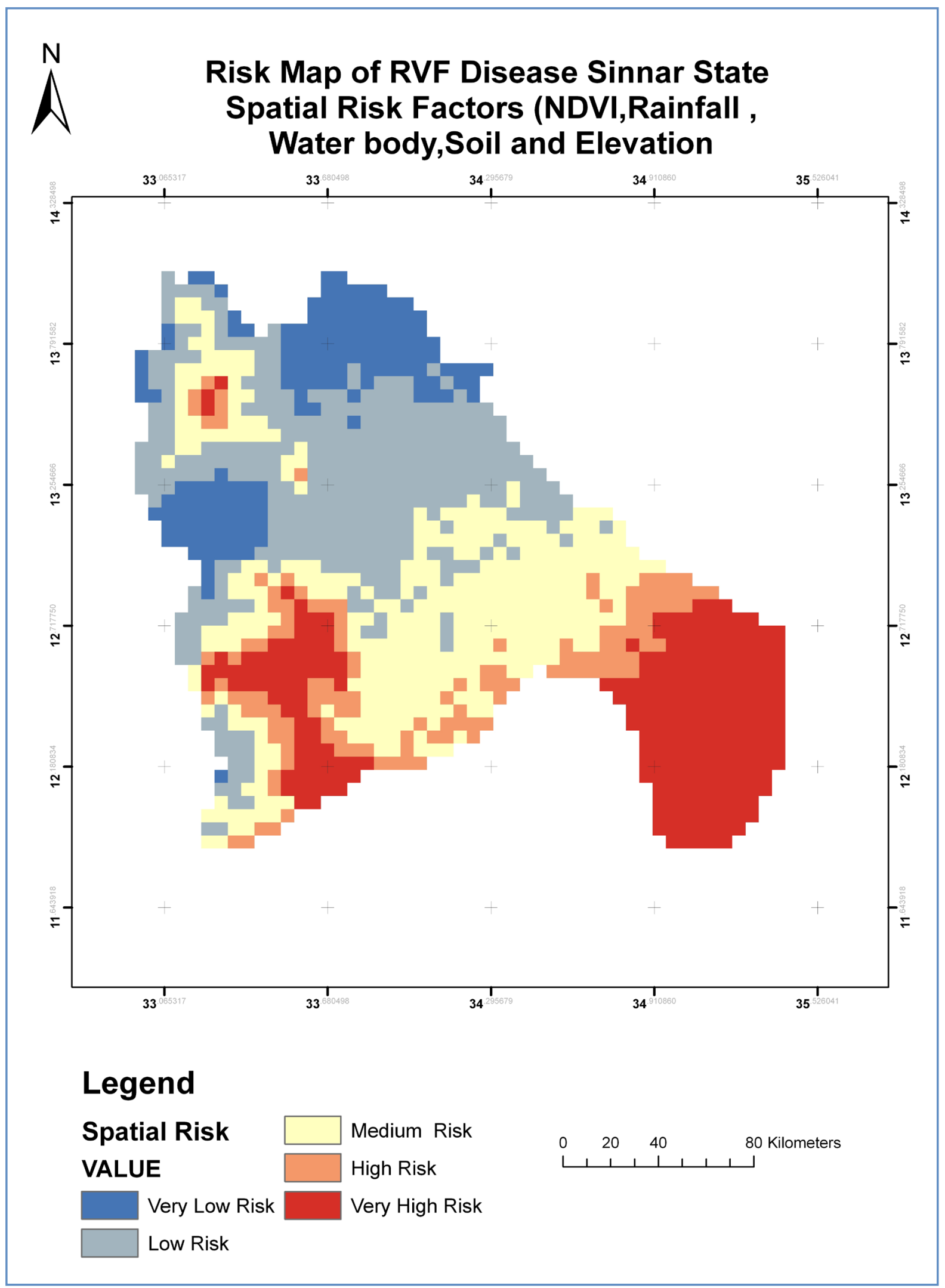

Figure 15. Risk map of RVF disease 2007 by Raster calculation combine environmental risk factors. 


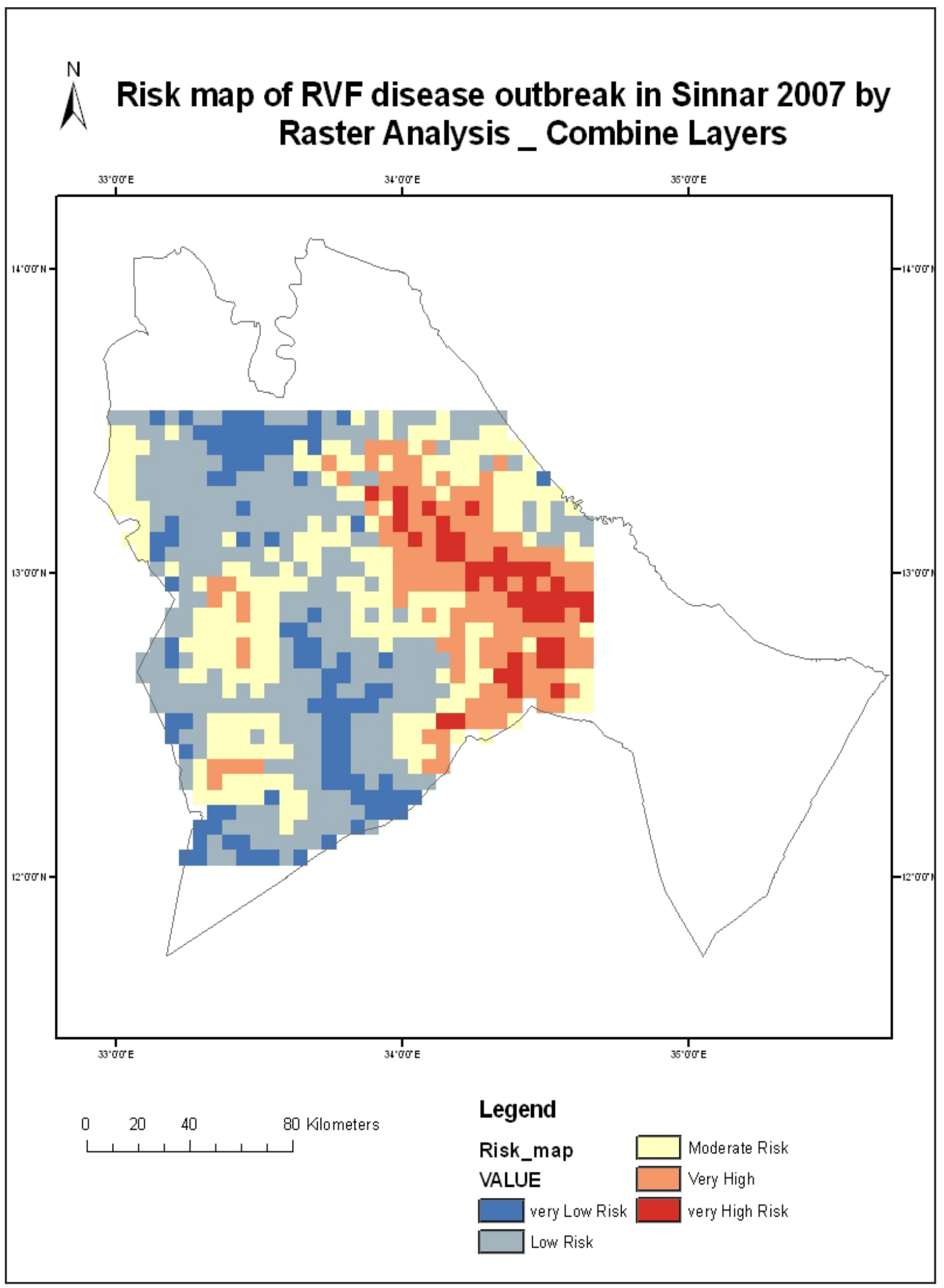

Figure 16. Risk map of RVF disease 2007 by raster calculation for environmental factors and animal route. 


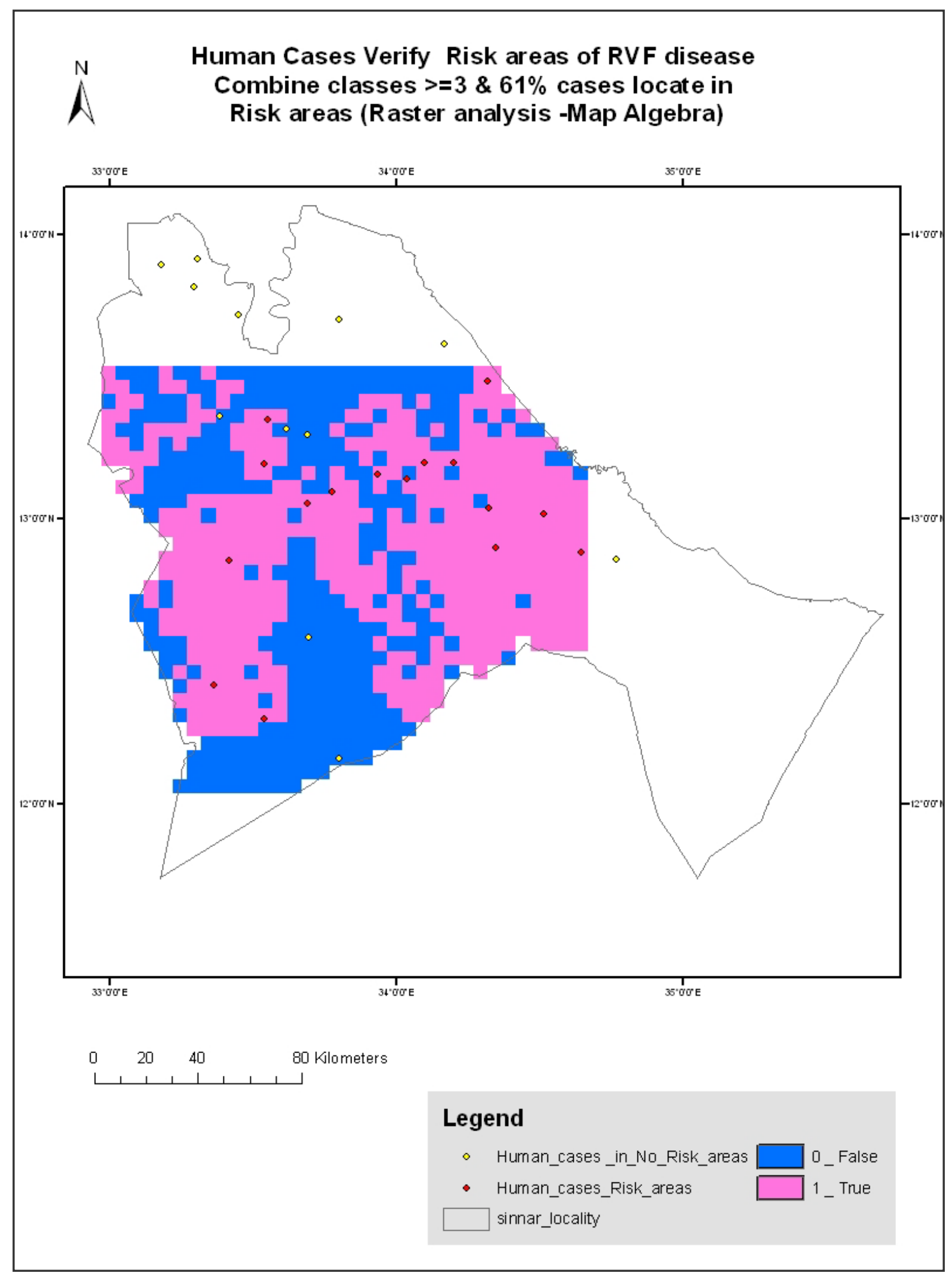

Figure 17. Risk map of RVF disease 2007 by raster analysis Boolean operation to find area meeting very high risk class $\geq 3$ of all risk factors layers (true : RVF risk areas; false: RVF potential epizootic areas). 
rainfall and the concomitant presence of large numbers of mosquitoes [8] Rift Valley Fever is usually found in tropical forest, Guinean and Sudanese zones but as well in semi-arid and arid zones that are associated with alluvial riverine floodplains that provide a suitable environment for mosquito breeding. An annual emergence of infected Aedes mosquitoes may occur in grassland areas with high rainfall in the tropical forest belt and the bushed and wooded savanna habitats with moderately high rainfall. Emergence of RVF infected Aedes may occur at 2 - 4 year intervals. In lower rainfall areas $(<500 \mathrm{~mm} / \mathrm{yr})$ of East and Southern Africa, epizootics of RVF generally occur at 5 - 15 year intervals, cycles of drought are followed by periods of excessive rainfall. These are the conditions that prevail throughout much of the epizootic areas of Kenya [9] and the resulting mosquitoes transfer the virus to the livestock on which they feed. Once the livestock is infected, other species of mosquitoes can become infected from the animals and can spread the disease. In addition, it is possible that the virus can be transmitted by other biting insects.

Average of rainfall mm (Abu Naama Station) in June-December for 13 years (2000-2012) as shown in Figure 3 indicated that highest rain occurred in 2007, 2010 and 2012. Compared with years of 1973, 2007, 1988, 2010 and 2012 the years of 1973 and 2007 were characterized by an average rainfall range between (467 - $525 \mathrm{~mm})$ and (587.4 - $786.7 \mathrm{~mm})$. Serologic surveys have detected RVF antibodies in domestic livestock and in humans from different Sudanese states including Nile, Khartoum, Kassala, El Gezira, Sinner, and White Nile, at 1973 [10] [11]. In 2007, alarge outbreak of RVF, characterized by abortion storms among domestic livestock and More than 25 human samples have been found positive for RVF by PCR or ELISA in White Nile and Sinnar and Gezira States (WHO, FMOH) 2007 [12]. When compare the average range of rainfall that occurred at 1973, 2007 to 1988, 2010 (462.1 - $922.5 \mathrm{~mm}$ ) and 2012 (497.9 - $676.2 \mathrm{~mm})$, the disease is expected to have happened but no information (Figure 18, Figure 19).

\subsection{Vegetation Indices}

NDVI, a measure of vegetation greenness, is often highly climate dependent. Rainfall amount coupled with types of soils that have high capacity of retaining moisture create suitable conditions for high NDVI values. NDVI also increases in low-lying areas when they are flooded for about 60 days [13] all those factors provide suitable conditions for mosquito breeding. Animals are attracted to these areas for fodder and water sources making them highly exposed to mosquito bites that can result in RVF epizootics. Our study has shown that NDVI can be good indicator for identifying high risk areas of RVF disease. Also irrigated area and forest represent a suitable environment for insects. Average of NDVI values 2007 represent NDVI range between $(-0.14123$ - 0.79979) were classified into 5 categories, very high, high, medium, low, very low associated with clinical cases (Figure 5), high RVF Risk areas are associated with NDVI equal and greater than 0.5. Short-term of NDVI average for 6 years (2007-2012), showed the different periods (Plates 1-6) and indicated the highest risk by area coverage for each year. The risk area is changing (increase or decrease) according to change of the NDVI average values from year to year, which is a result of amount cumulative rainfall during the year. These are designated as two good indicators of Rift Valley fever disease occurrence. The observed increase NDVI risk area coverage (number of pixels) in the years 2007, 2010 and 2012 is shown in (Table 1).

\subsection{Soil Type and Topographic Position (DEM)}

The factors helping to create a suitable environment for vectors represented in low-lying areas where rain water collected and soil type that hold these waters more than other types, such as alluvial, and, clay soil and basement complex soil as show in (Figure 11). Figure 6 and Figure 7 show the digital elevation model (DEM) of Sinnar State associated with clinical cases and Figure 12 reclassify (DEM). Most of the area is characterized by clay soil and located in low areas. Drainage courses and low lying sites represent areas for collection of rain water, which provides a suitable environment for breeding vector. Some female mosquitoes lay their eggs directly on the water surface. Others lay their eggs on substrates above the water line (flood pool mosquitoes) and the eggs hatch upon flooding. In some cases, the eggs will remain viable for several years until further flooding occurs. According to drainage way size and the intensity of rainfall, the distributed water bodies are favorable environment to the development of Aedes mosquito populations. Mosquitoes of the genus Aedes that breed in temporary ground pools are known in East Africa as "Dambos". This is due to the widespread and prolonged heavy rainfall that raises the water table in certain areas. The flooded grassland and depressions provide the breeding habitats for Aedes mosquitoes [13]. In this regard the high risk by locality was found in: 

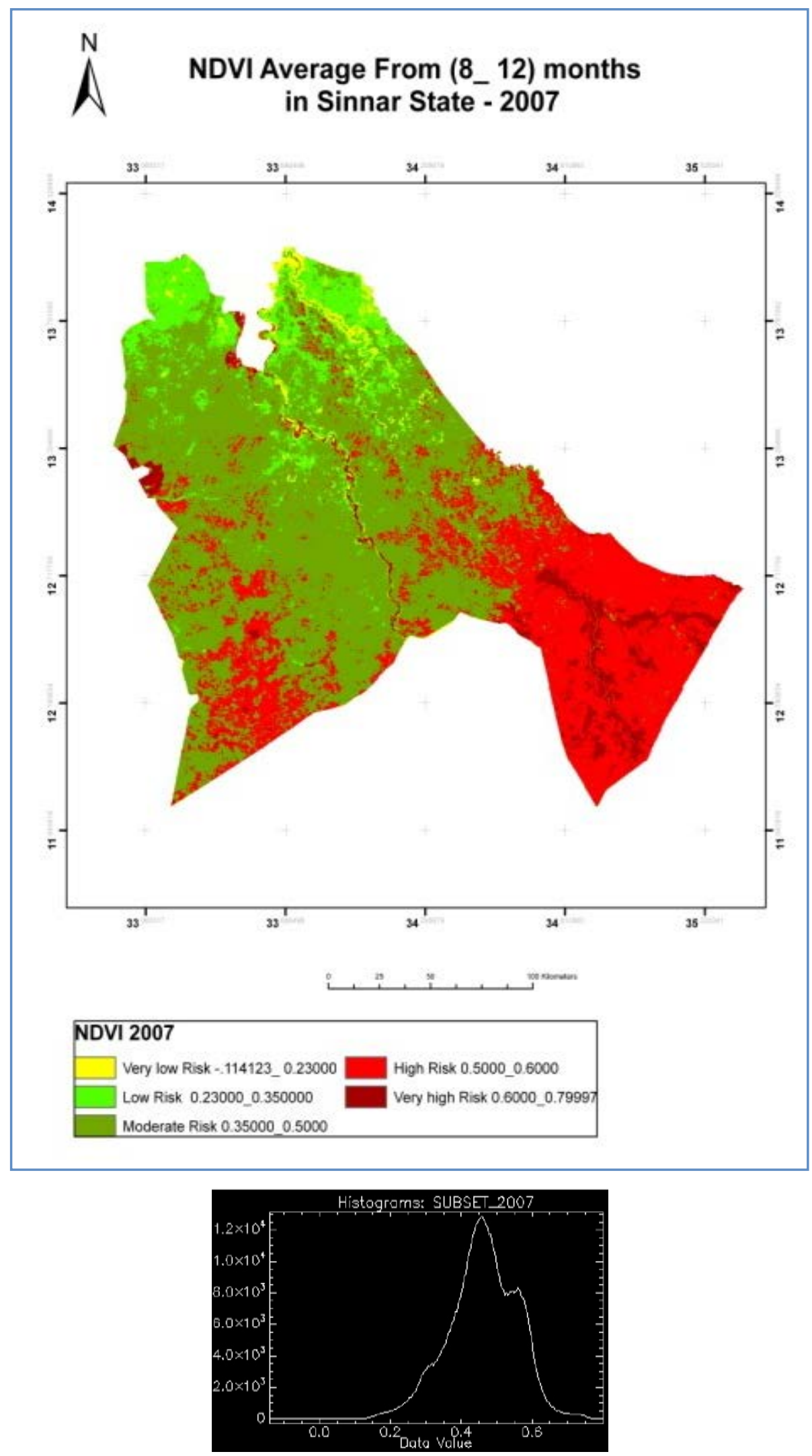

Plate 1. NDVI classification of (NDVI) values for 2007 with histogram. 

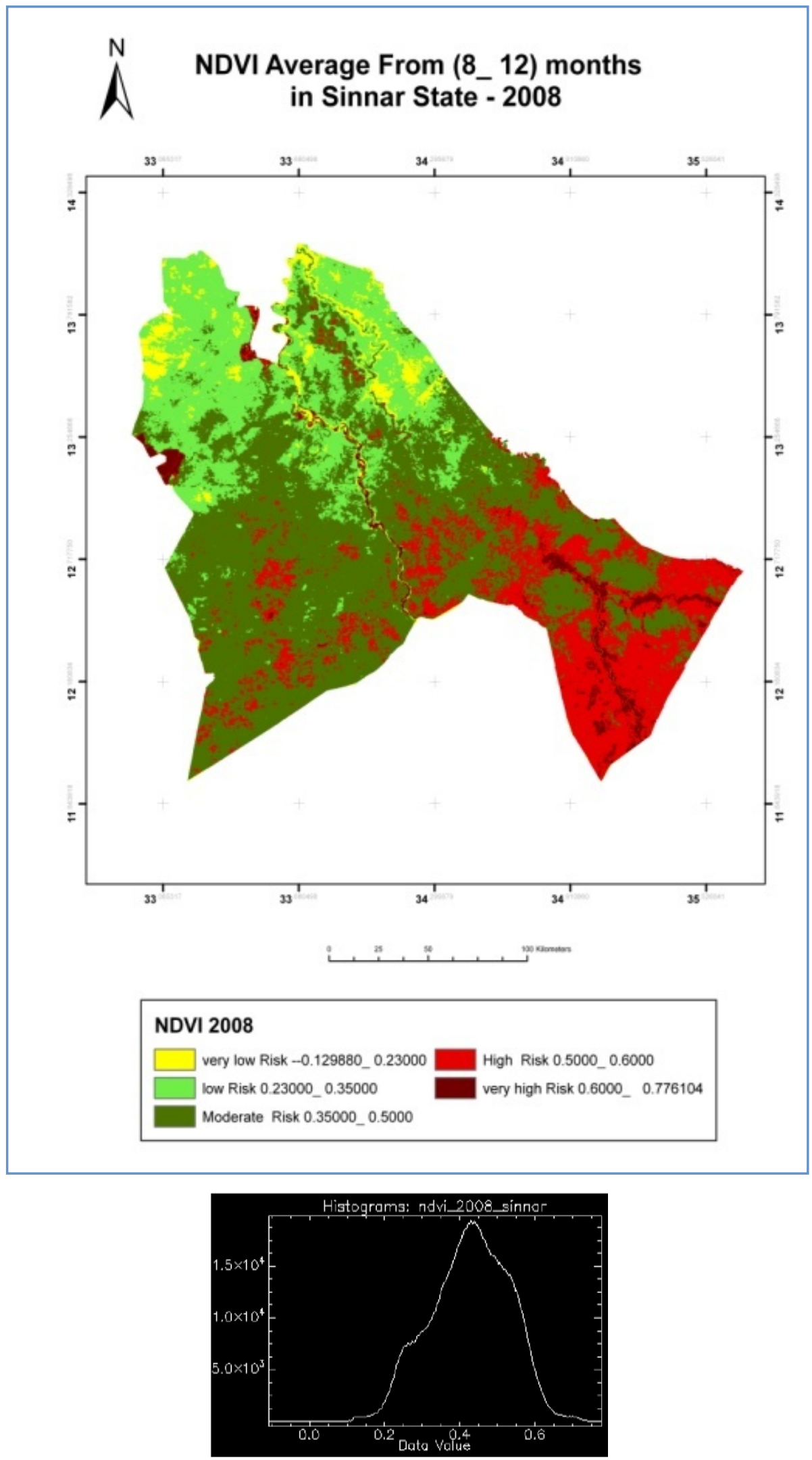

Plate 2. NDVI classification of (NDVI) values for 2008 with histogram. 

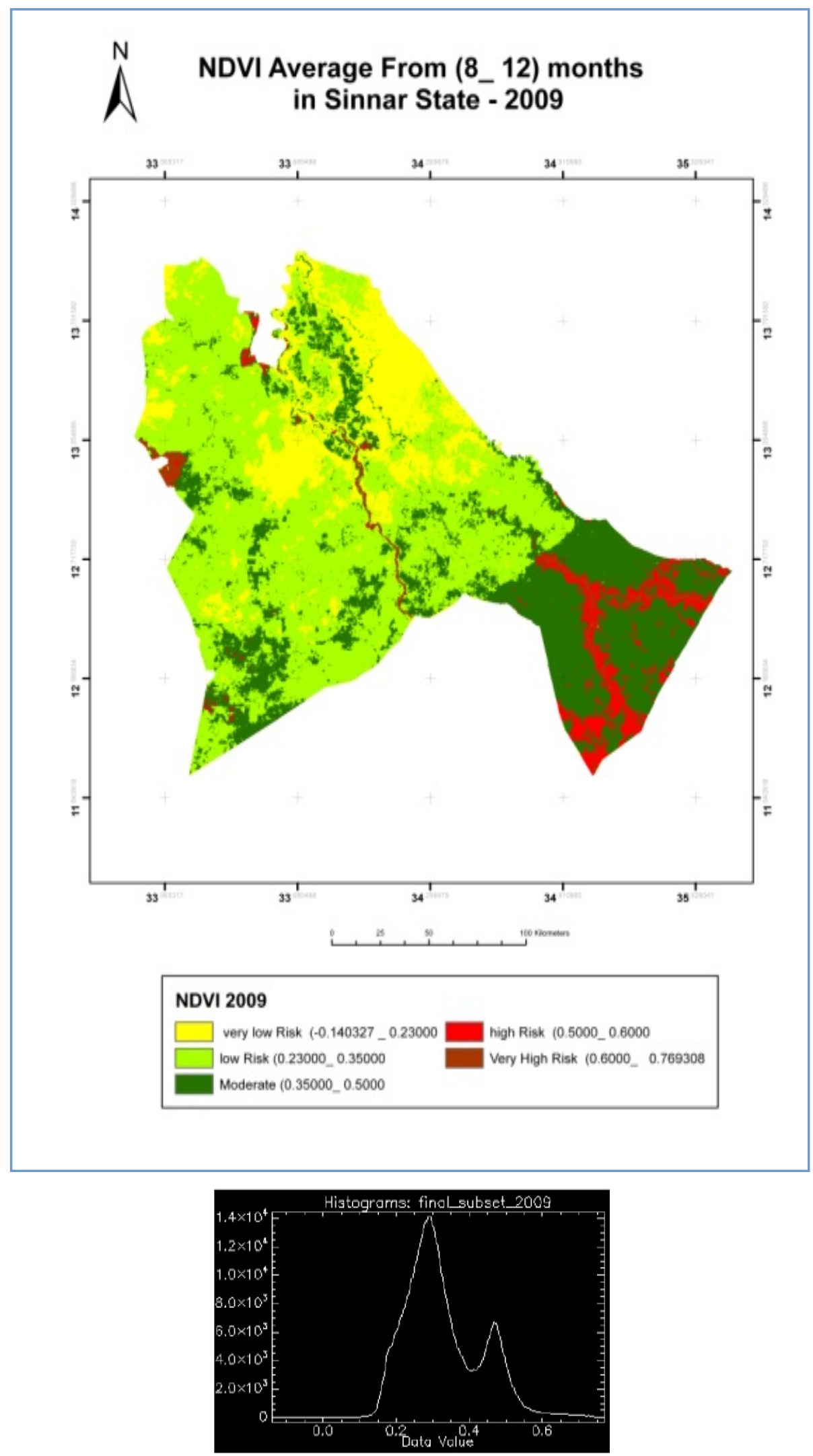

Plate 3. NDVI classification of (NDVI) values for 2009 with. 

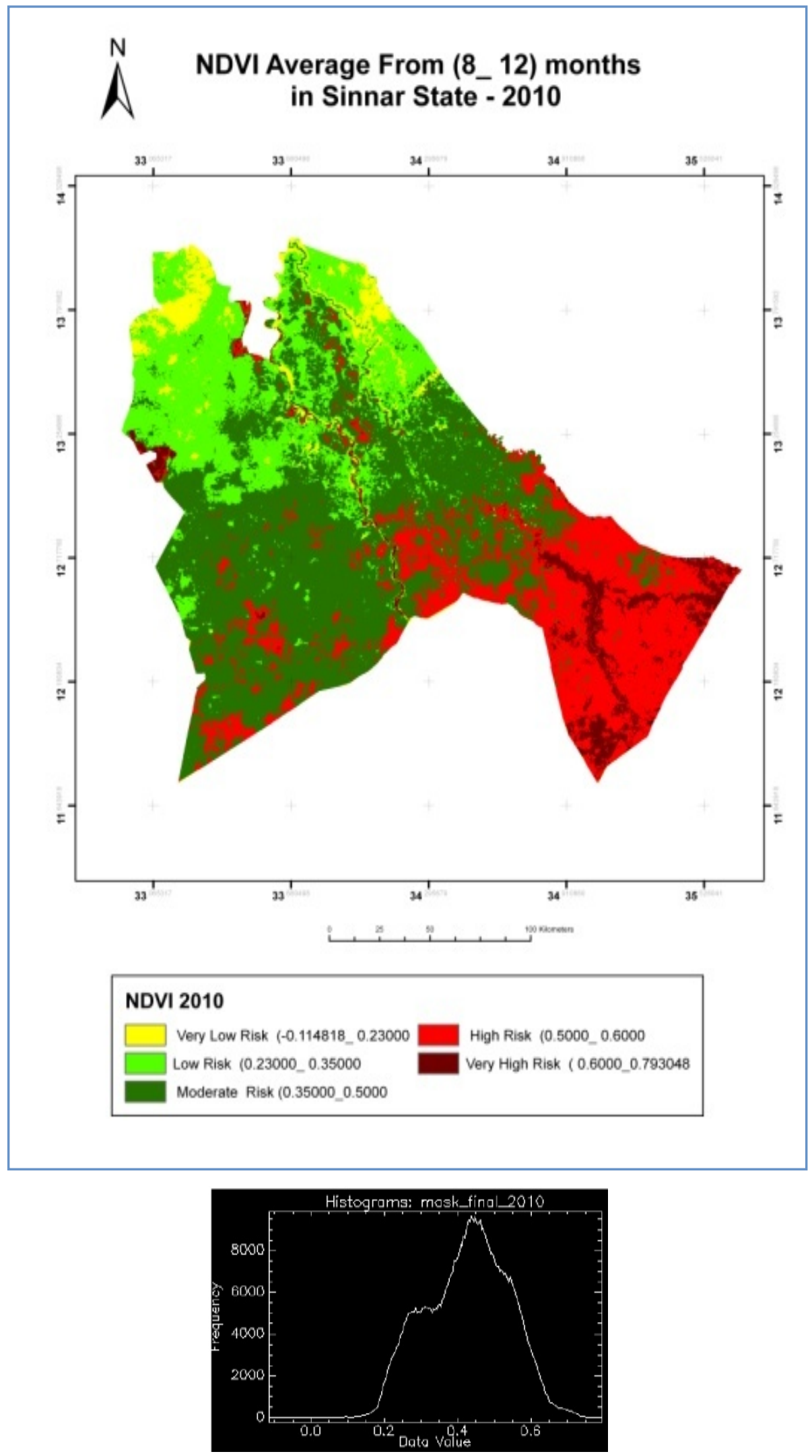

Plate 4. NDVI classification of (NDVI) values for 2010 with histogram. 

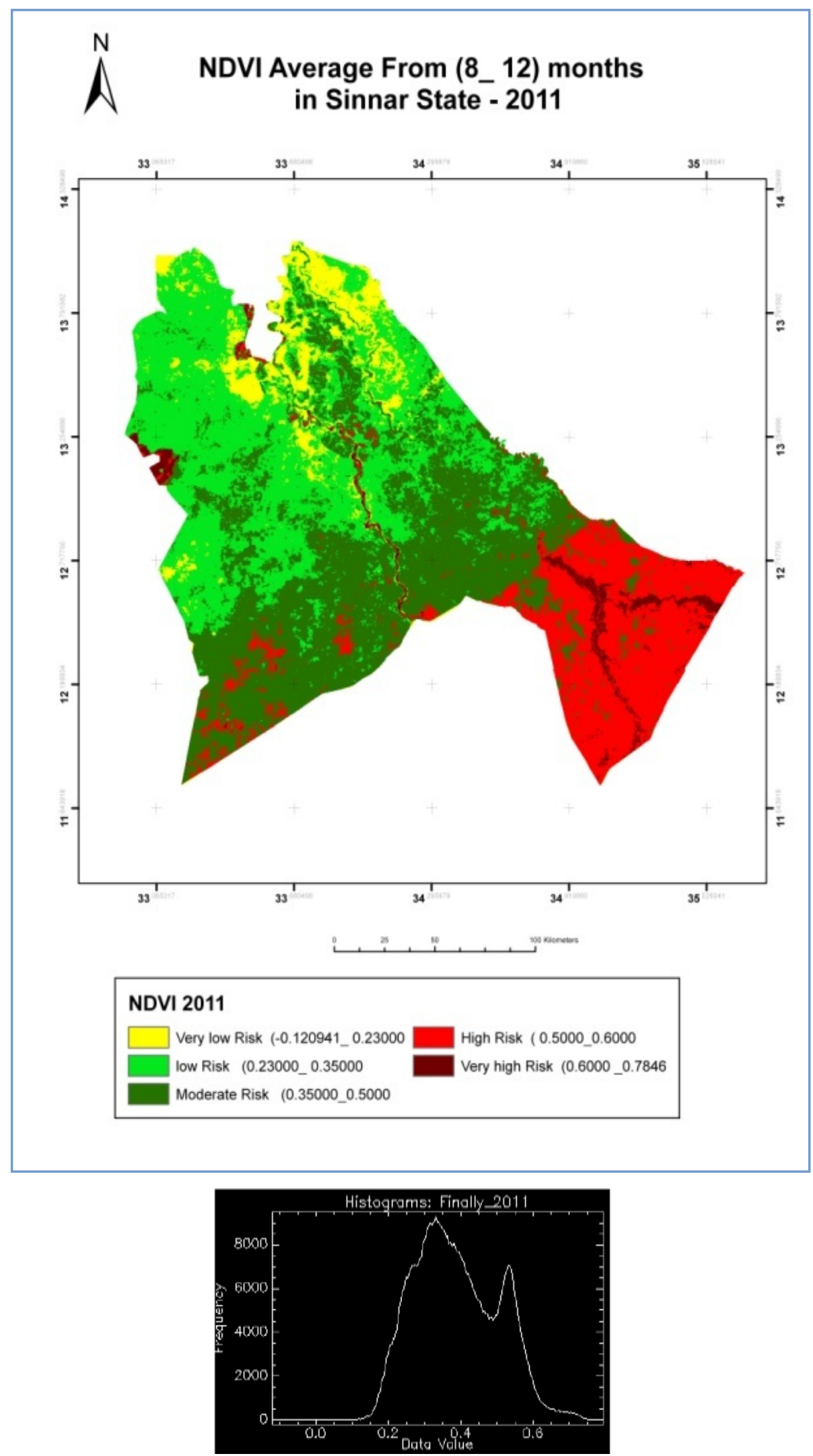

Plate 5. NDVI classification of (NDVI) values for 2011 with histogram. 

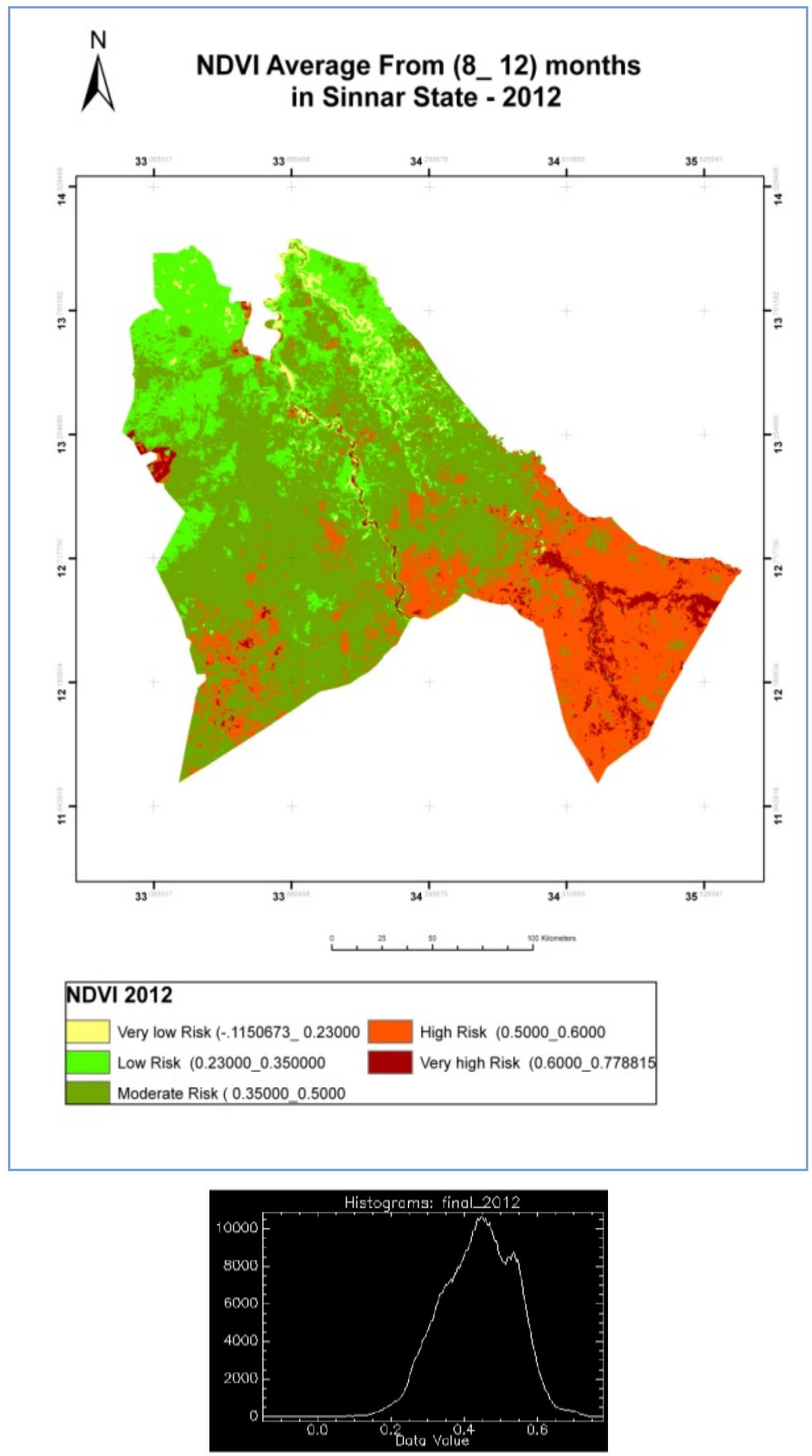

Plate 6. NDVI classification of (NDVI) values for 2012 with histogram. 


\section{Comprison Total Rainfall Mm for 13 years (2000-- 2012)}

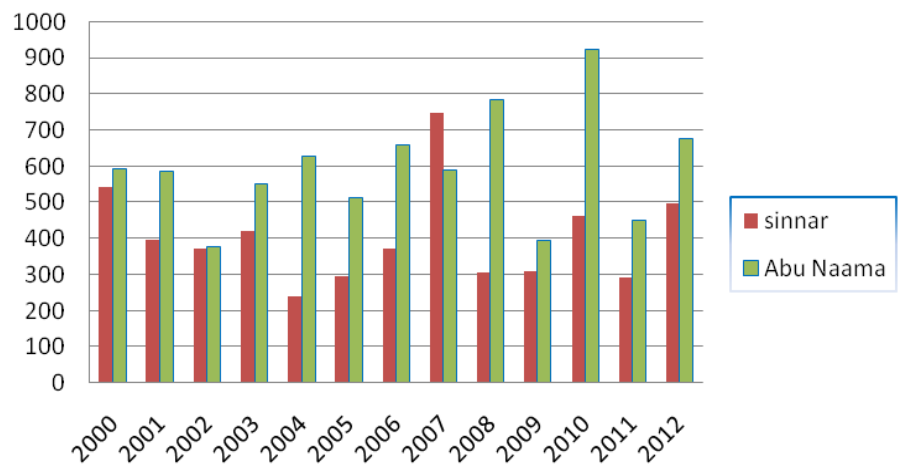

Figure 18. Average of rainfall (Abu Naama Sinnar Stations) in rain.

Comprison Total Rainfall (Mm)

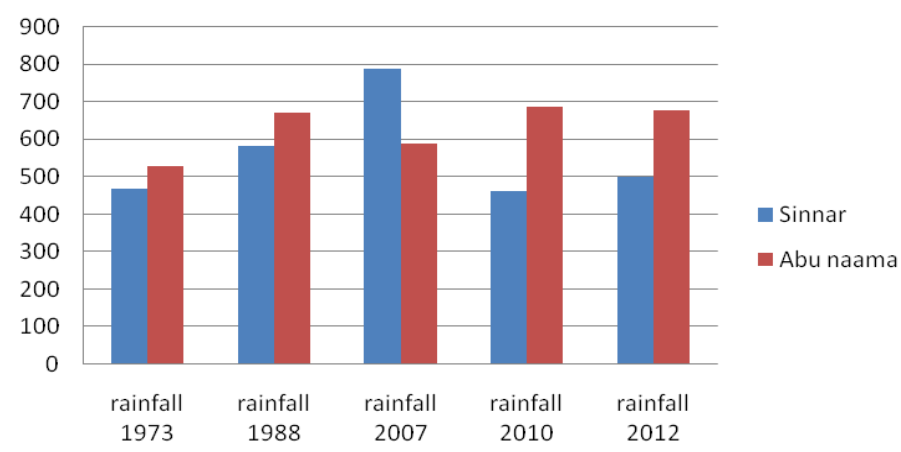

Figure 19. Comparison rainfall data analysis 1973 \& 2007 relative to RVF disease and with others years.

Table 1. NDVI average value \& high risk area coverage.

\begin{tabular}{|c|c|c|c|}
\hline Year & NDVI average value & $\begin{array}{l}\text { High risk area converge } \\
(0.5-0.6) \text { value }\end{array}$ & $\begin{array}{l}\text { High risk area coverage } \\
\text { greater than }(0.6) \text { values }\end{array}$ \\
\hline 2007 & $-0.14123-0.79979$ & $11403.564 \mathrm{Km}^{2}$ & $2378,600 \mathrm{Km}^{2}$ \\
\hline 2008 & $-0.10843-0.77627$ & $8265.424 \mathrm{Km}^{2}$ & $1161.447 \mathrm{Km}^{2}$ \\
\hline 2009 & $-0.01257-0.7618$ & $1965.101 \mathrm{Km}^{2}$ & $458.740 \mathrm{Km}^{2}$ \\
\hline 2010 & $0.114818-0.793048$ & $8959.276 \mathrm{Km}^{2}$ & $2133.452 \mathrm{Km}^{2}$ \\
\hline 2011 & $0.120941-0.7846$ & $7332.327 \mathrm{Km}^{2}$ & $1.153 .075 \mathrm{Km}^{2}$ \\
\hline 2012 & $0.150673-0.778815$ & $10113.478 \mathrm{Km}^{2}$ & $1458.598 \mathrm{Km}^{2}$ \\
\hline
\end{tabular}

- Al Dinder Locality (19 cases) expected as depressional areas often harbour the most favourable conditions for the survival and proliferation of Aedes spp. (i.e. Low ground, water body and the surrounding flooded territory associated with alluvial riverine floodplains and dense vegetation. In addition livestock is often concentrated in the gently undulating clay plains where watering points and grazing areas are found (Figure 3, Figure 5, Figure 6 and Figure 11).

- Adaly wa Almazmum Locality (20 cases) Some Clinical cases found on some parts scattered mountain presence at Aldaly wa Almazmum Locality. This can be explained by the presence of localized forests, relativel high rainfall and animal's continuous movements. These protected locations could have more humid conditions than surrounding flat plains. These conditions could possibly favour the survival of vectors Shown by Figure 3, Figure 5, Figure 6 and Figure 11. 


\subsection{Livestock Routes}

RVF virus primarily affects livestock and can cause disease in a large number of domestic animals (this situation is referred to as an "epizootic"). Moved infected animals from an infected area to a zone free of the disease and remain in direct contact is the main way of transmission. The presence of an RVF epizootic can lead to an epidemic among humans who are ex-posed to diseased animals. Human infections result from the bites of infected mosquitoes or contact with the blood of infected animals. The virus can be transmitted to humans through the handling of animal tissue during slaughtering or butchering, assisting with animal births. Ruminant-to-human transmission is the main infection route for humans, although they can also be infected by mosquito bites [14] patrons, farmers, slaughterhouse workers and veterinarians are at higher risk of infection. In the outbreak of 2007 in Sudan, 65\% infected human were patrons, 17\% were farmers, 13\% Young age and 5\% other. Role of animal routes as explained in corresponding map with clinical cases in study area is shown in Figure 3.

\section{Conclusions}

- High Rainfall in low lying areas with dense NDVI was highly correlated with increase of RVF disease. These environmental factors were verified through the use of human cases in outbreak of 2007. It was observed that $85 \%$ human cases of RVF disease corresponded to 500 to 700 cumulative rainfalls and $46 \%$ human cases of RVF disease corresponded to $\geq 0.5$ NDVI value with 500 to 700 cumulative rainfalls. As well, $67.8 \%$ human cases of RVF disease corresponded to $\geq 0.4$ NDVI value with 500 to 700 cumulative rainfalls.

- Highest Risk area was identified by combining all reclassified risk factors (NDVI average values, cumulative rainfall, water body, soil type, DEM, Animal route). Raster calculation provided a powerful tool for performing multiple tasks. $61 \%$ human cases of RVF were located in risk areas (combine classes $\geq 3$ ) of risk map.

- Short-term of NDVI average for 6 years (2007-2012) indicated that highest risk area coverage increased with the increase in NDVI average values

- All earlier results and conclusions from the study area which identified the high risk areas of RVF disease could be a good indicator to predict that "high-risk area for the Rift Valley fever disease occurred in areas characterized by rainfall between 500 - $700 \mathrm{Mm}$. NDVI values were equal and greater than 0.5, clay soils, depressions sites, presence of water body and existing hosts (humans and animals). All of these factors represented an appropriate environment for Aedes mosquitoes' presence and its activity to transmit the RVF disease and other vector borne diseases.

- The results of study area could be generalized for all other similar parts of the country to produce prediction of maps for RVF disease in Sudan.

- GIS was recommended to utilize for RVF disease control by using analytical tools which had the adequate potential and the capability. It enabled performing multiple tasks about spatial distribution and relationship with the environmental factors and the analysis of disease. It was also indispensible for planning and designing forecasting models and early warning systems for RVF. This could be carried out by using satellite images and incorporating rainfall and NDVI from the freely available satellite and weather data so as to provide measures to improve the control of the disease.

\section{Acknowledgements}

All praise to the god. After hardworking, this thesis is finally completed.

I would like to extend my sincere appreciation to Dr. Ahmed Mustafa Hassan Epidemiology Veterinary Expert for guiding and discussing with me through the epidemiological disease information and advice throughout this project.

I am grateful to Agricultural Engineer Enas Ismail Abdalla (Federal Ministry of Agriculture and Irrigation) for her assistance invaluable time. I would also like to thank Sudan Central Bureau of Statistics \& Ministry of Health for polite dealing in giving information. Finally, I would like to extend my thanks to my family for their patience and understanding and I would like to extend my thanks to my friends and colleagues.

\section{References}

[1] Bishop, D.H., Calisher, C.H., Casals, J., Chumakov, M.P., Gaidamovich, S.Y., Hannoun, C., Lvov, D.K., Marshall, 
I.D., Oker-Blom, N., Pettersson, R.F., Porterfield, J.S., Russell, P.K., Shope, R.E. and Westaway, E.G. (1980) Bunyaviridae. Intervirology, 14, 125-143. http://dx.doi.org/10.1159/000149174

[2] Bhatt, B.M. and Joshi, J.P. (2012) GIS in Epidemiology: Applications and Services. National Journal of Community Medicine, 3, 259-263. http://njcmindia.org/uploads/3-2_259-263.pdf

[3] Pfeiffer, D., Costard, S., Stevens, K., Metras, R., Theuri, W., Kruska, R., Randolph, T., Grace, D. and Hendrickx, S. (2009) Risk Mapping for HPAI H5N1 in Africa Improving Surveillance for Bird Flu, 4-9.

[4] Ministry of Health (MOH) (2007) Report Outbreak 2007. Khartoum.

[5] Central Bureau of Statistics. Sinnar State Rainfall 1973, 1988 and from 2000 to 2012. Khartoum.

[6] MODIS Images Sinnar State from 2007 to 2012. http://reverb.echo.nasa.gov/reverb

[7] 2008 and 2011. Http://asterweb.jpl.nasa.gov/gdem.asp

[8] Linthicum, K.J., Anyamba, A., Tucker, C.J., Kelley, P.W., Myers, M.F. and Peters, C.J. (1999) Climate and Satellite in Dicators to Forecast Rift Valley Fever Epidemics in Kenya. Science, 285, 397-400.

[9] Davies, F.G. (1990) Rift Valley Fever in the Sudan. Transactions of the Royal Society of Tropical Medicine and Hygiene, 84, 141-147. http://dx.doi.org/10.1016/0035-9203(90)90410-G

[10] Eisa, M., Obeid, H.M.A. and El Sawi, A.S.A. (1977) Rift Valley fever in the Sudan. I. Results on Field Investigations of the First Epizootic in Kosti District, 1973. Bulletin of Animal Health and Production in Africa, 25, 343-347.

[11] Eisa, M. and Obeid, H.M.A. (1977) Rift Valley fever in the Sudan. II. Isolation and Identification of the Virus from a Recent Epizootic in Kosti District, 1973. Bulletin of Animal Health and Production in Africa, 25, 349-355.

[12] World Health Organization. Global Alert and Response (2012) Rift Valley Fever in Sudan. http://www.who.int/csr/don/2007_11_05/en/index.html

[13] Davies, F.G., Linthicum, K.J. and James, A.D. (1985) Rainfall and Epizootic Rift Valley Fever. Bulletin of the World Health Organization, 63, 941-943.

[14] Davies, F.G. and Martin, V. (2006) Recognizing Rift Valley Fever. Veterinaria Italiana, 42, 31-53. 


\section{Appendixes}

A.1. Matching the NDVI Values with Human Cases

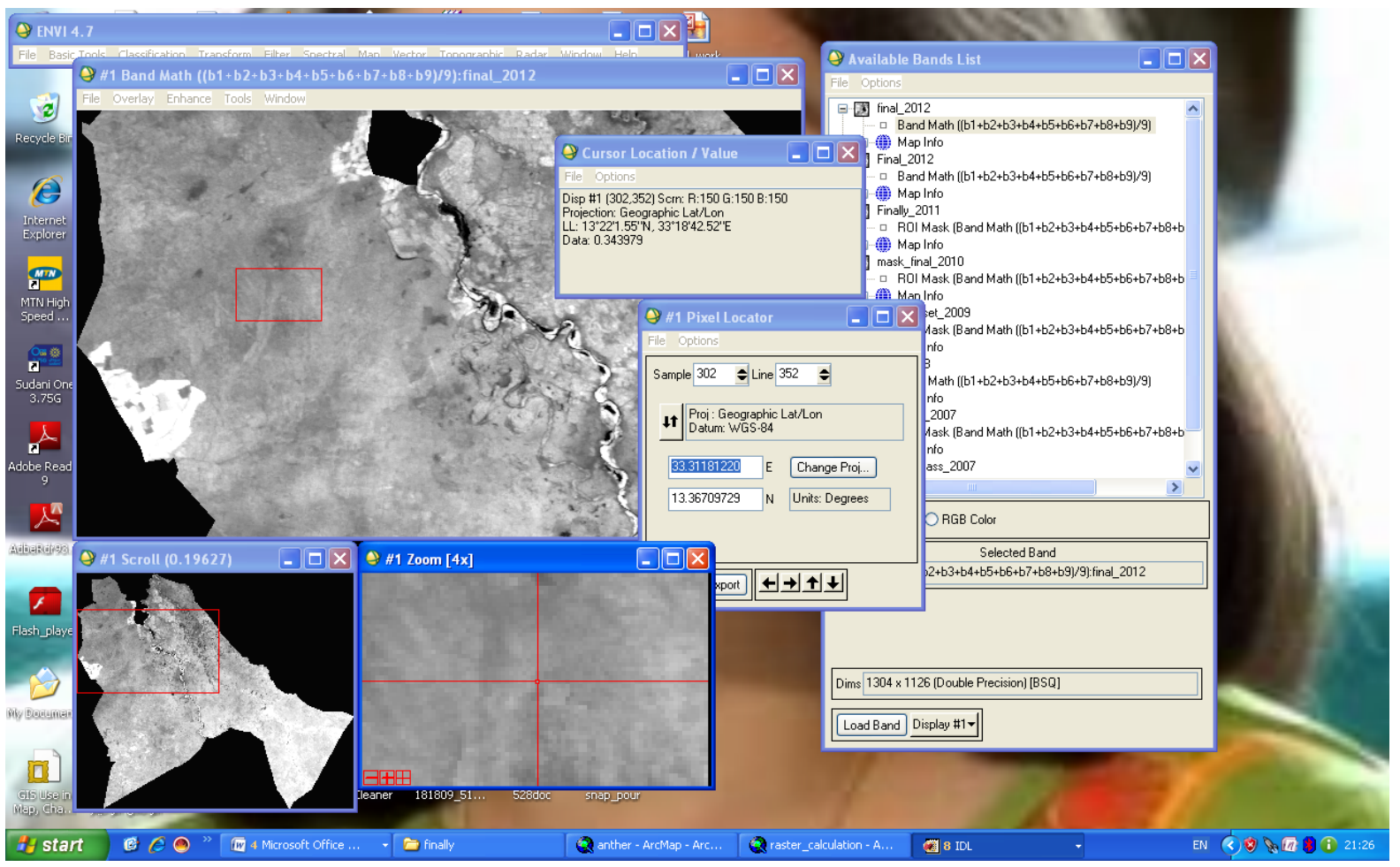

A.2. Show the Highest Risk by Area Coverage NDVI 2007 from (0.6 - 0.799) Values as 2,378,600 KM2

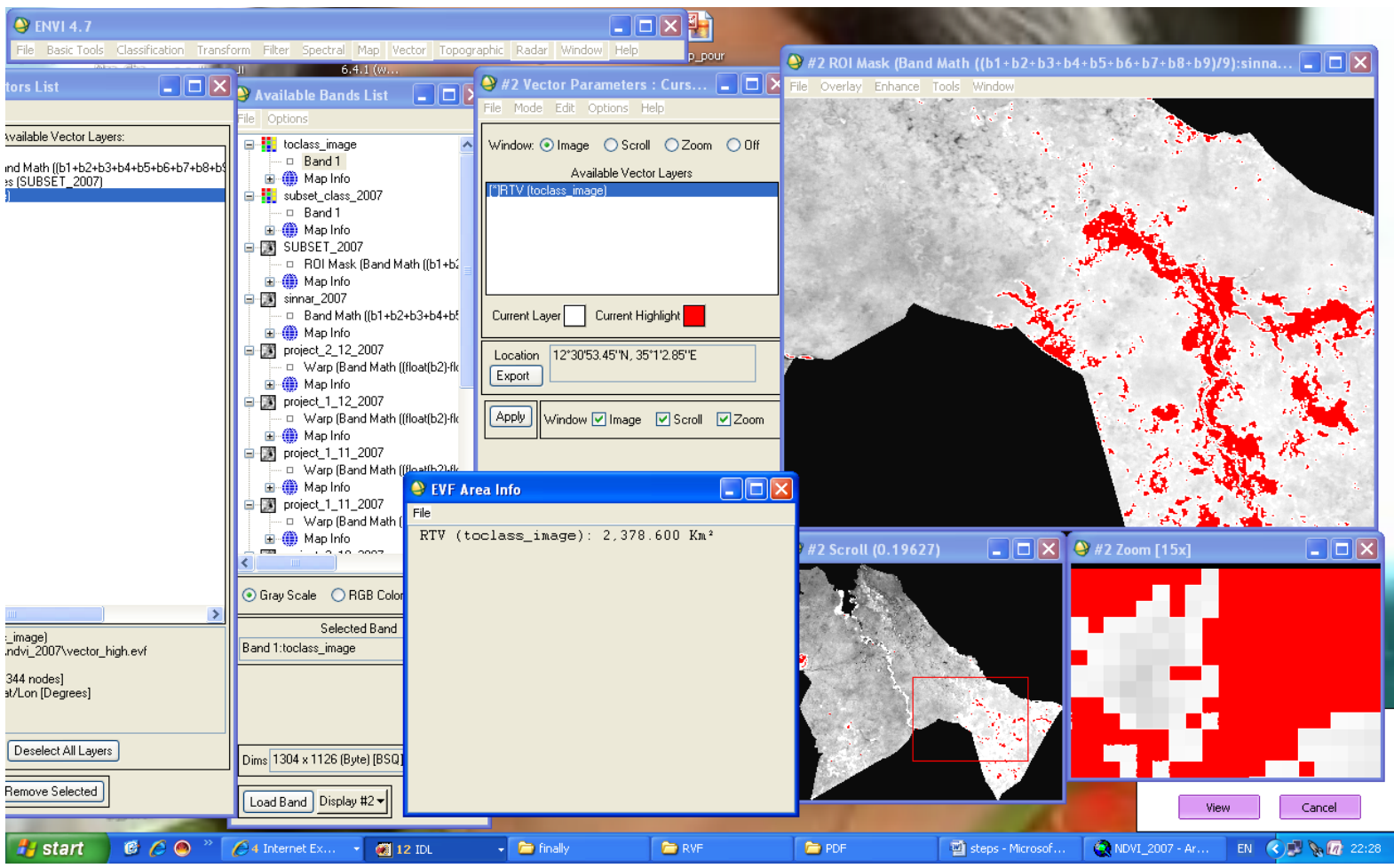


A.3. Table Manipulation-Selection by Attribute the Human Disease Clinical Case Points Correspond to $\geq 0.5$ NDVI Values and (500 - 700) Mm Rainfall to Determine the High Risk Area of RVF Disease

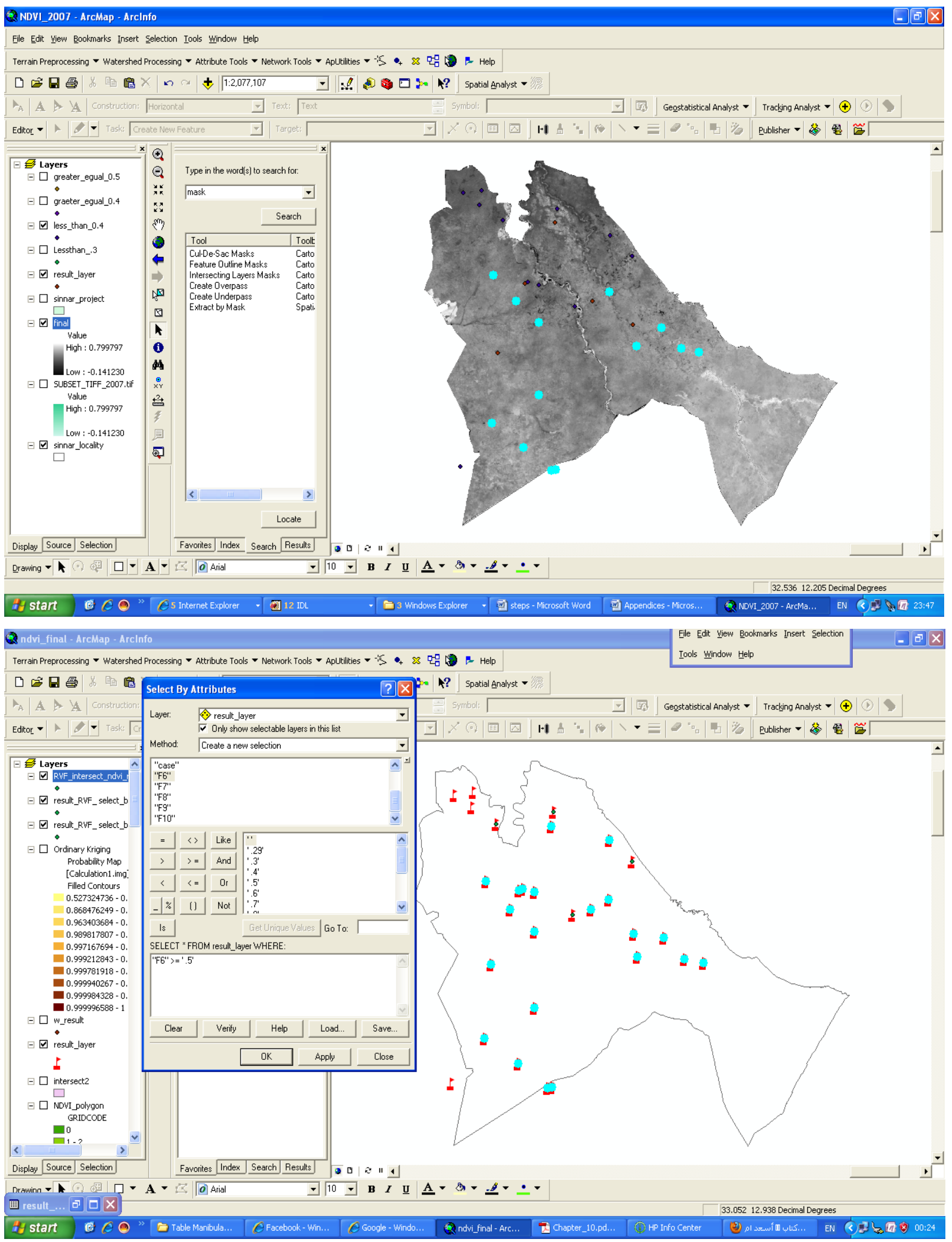

